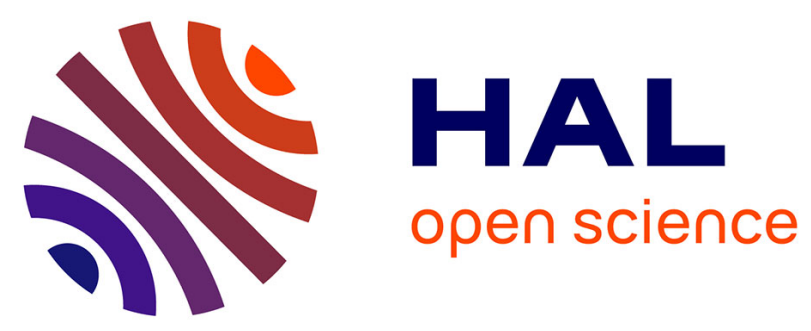

\title{
Straightforward Synthesis of Well-Defined Poly(vinylidene fluoride) and Its Block Copolymers by Cobalt-Mediated Radical Polymerization
}

Panagiotis Falireas, Vincent Ladmiral, Antoine Debuigne, Christophe

Detrembleur, Rinaldo Poli, Bruno Ameduri

\section{To cite this version:}

Panagiotis Falireas, Vincent Ladmiral, Antoine Debuigne, Christophe Detrembleur, Rinaldo Poli, et al.. Straightforward Synthesis of Well-Defined Poly(vinylidene fluoride) and Its Block Copolymers by Cobalt-Mediated Radical Polymerization. Macromolecules, 2019, 52 (3), pp.1266-1276. 10.1021/acs.macromol.8b02252 . hal-02017774

\section{HAL Id: hal-02017774 \\ https://hal.science/hal-02017774}

Submitted on 1 Mar 2021

HAL is a multi-disciplinary open access archive for the deposit and dissemination of scientific research documents, whether they are published or not. The documents may come from teaching and research institutions in France or abroad, or from public or private research centers.
L'archive ouverte pluridisciplinaire HAL, est destinée au dépôt et à la diffusion de documents scientifiques de niveau recherche, publiés ou non, émanant des établissements d'enseignement et de recherche français ou étrangers, des laboratoires publics ou privés. 


\section{Straightforward synthesis of well-defined poly(vinylidene fluoride) and its block copolymers by cobalt-mediated radical polymerization}

Panagiotis G. Falireas, ${ }^{\dagger}$ Vincent Ladmiral, ${ }^{\dagger}$ Antoine Debuigne, ${ }^{+}$Christophe

Detrembleur,,${ }^{+}$Rinaldo Poli, ${ }^{*}, \xi, \approx$ and Bruno Ameduri ${ }^{*}, \dot{\dagger}$

${ }^{\dagger}$ ICGM CNRS, Univ Montpellier, ENSCM, Montpellier, France.

¥Center for Education and Research on Macromolecules (CERM), CESAM Research Unit, University of Liege, Sart-Tilman B6a, 4000 Liege, Belgium

${ }^{\S}$ CNRS, LCC (Laboratoire de Chimie de Coordination) and Université de Toulouse, UPS, INPT, 205 route de Narbonne, BP 44099, 31077 Toulouse Cedex 4, France

Submitted for publication in Macromolecules 


\title{
Straightforward synthesis of well-defined poly(vinylidene fluoride)
} and its block copolymers by cobalt-mediated radical polymerization

Panagiotis G. Falireas, ${ }^{\dagger}$, Vincent Ladmiral, ${ }^{\dagger}$ Antoine Debuigne, ${ }^{\dagger}$ Christophe

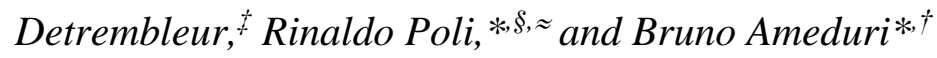

${ }^{\dagger}$ ICGM CNRS, Univ Montpellier, ENSCM, Montpellier, France.

Center for Education and Research on Macromolecules (CERM), CESAM Research Unit, University of Liege, Sart-Tilman B6a, 4000 Liege, Belgium

${ }^{\S}$ CNRS, LCC (Laboratoire de Chimie de Coordination) and Université de Toulouse, UPS, INPT, 205 route de Narbonne, BP 44099, 31077 Toulouse Cedex 4, France

$\approx$ Institut Universitaire de France, 1, rue Descartes, 75231 Paris Cedex 05, France

*Corresponding Authors: E-mail: bruno.ameduri@enscm.fr (B. Améduri)

E-mail: rinaldo.poli@1cc-toulouse.fr (R. Poli)

\begin{abstract}
The organometallic-mediated radical polymerization (OMRP) of vinylidene fluoride (VDF) using an alkyl cobalt(III) compound as initiator was recently proven successful for the controlled synthesis of PVDF (Angew. Chem. Int. Ed. 2018, 57, 2934-2937). However, the required synthesis of the organometallic initiator renders this method labor-intensive and time consuming. The present contribution reports the straightforward synthesis of well-defined poly(VDF) and its block copolymers via OMRP performed using a two-component initiating system from readily available compounds. First, PVDF was obtained by redox initiation using the combination of a peroxide initiator and bis(acetylacetonato)cobalt(II), $\left(\mathrm{Co}(\mathrm{acac})_{2}\right)$. This step was optimized in terms of the initiator choice, polymerization temperature and reactant molar ratio. The best results regarding the molar mass control and the dispersities were obtained using bis(tert-butylcyclohexyl) peroxydicarbonate as initiator at $60{ }^{\circ} \mathrm{C}$. The polymerization followed a first order kinetics and the molar masses of PVDF increased linearly up to a $27 \%$ conversion to reach $11,800 \mathrm{~g} / \mathrm{mol}$ with low dispersities $(~(D=1.35)$. Chain extension of the resulting PVDF-Co(acac) 2 with vinyl acetate (VAc) led to three diblock copolymers of various chain lengths.
\end{abstract}




\section{Introduction}

Fluoropolymers are outstanding niche polymers with exceptional properties. They found many applications in high-tech domains. Among them, $\mathrm{PVDF},{ }^{1}$ is the second largest commercially available fluoropolymer after polytetrafluoroethylene (PTFE). It exhibits remarkable properties such as piezo- and ferroelectric, hydrophobic and oleophobic properties, low dielectric constants, chemical inertness to acids and solvents, and excellent weathering. ${ }^{1-4}$ It has been involved in many valuable applications such as coatings, ${ }^{4}$ aerospace and aeronautics, backsheets for photovoltaic items, piezo/ferroelectric devices, ${ }^{5,6}$ and functional membranes for water treatment, ${ }^{7}$ and for biomedical applications. ${ }^{8}$ As several other fluoropolymers, PVDF can only be synthesized by radical polymerization but leads to some defects of VDF-VDF chaining. ${ }^{9}, 10$ The VDF monomer is not explosive and much less toxic than TFE, chlorotrifluoroethylene $(\mathrm{CTFE})^{11}$ or other fluoromonomers. ${ }^{3}$

Though several techniques of reversible deactivation radical polymerization of VDF have been reported, ${ }^{12-19}$ the importance of PVDF has stimulated the search for nonradical methods for VDF polymerization. Indeed, reaching high molar mass while keeping low contents of reverse addition (head to head, $\mathrm{H}-\mathrm{H}$, and tail to tail, T-T) is quite challenging. For example, Liepins et al. ${ }^{20}$ achieved the room temperaturesynthesis of PVDF inducing a low $\mathrm{H}-\mathrm{H}$ chain defects content using a modified ZieglerNatta Catalyst. This catalyst did not afford any control over the polymerization.

Efforts aimed at producing PVDF with controlled molar mass and low dispersity for macromolecular engineering by reversible deactivation radical polymerization (RDRP) methods has so far met with limited success. Though the RDRP of VDF was pioneered in the late $70 \mathrm{ies},{ }^{21}$ only three techniques have been reported so far: (i) iodine transfer polymerization (ITP), ${ }^{3,12-14,22,23}$ (ii) reversible addition fragmentation chain transfer 
(RAFT) polymerization, ${ }^{15-19}$ and (iii) organometallic-mediated radical polymerization (OMRP) ${ }^{24}$ The first two techniques need the use of a radical initiator and a suitable chain transfer agent (CTA), which ensures the reversible degenerative transfer (DT) in the ITP and RAFT processes. Both were shown to produce relatively well-defined diblock $^{3,12,18,22,25}$ and triblock ${ }^{3,11,22}$ copolymers. However, the chain defects resulting from head to head $\left(\mathrm{H}-\mathrm{H},-\mathrm{CH}_{2}-\mathrm{CF}_{2}-\mathrm{CF}_{2}-\mathrm{CH}_{2}-\right)$ VDF-VDF additions impose limits on the number average molar masses $\left(M_{n} \mathrm{~s}\right)$ and dispersities $(\bigoplus \mathrm{s})$ attainable by these two techniques, as demonstrated in both $\mathrm{ITP}^{22}$ and $\mathrm{RAFT}^{15,17}$ polymerizations. The bottleneck is the stronger PVDF-X bond in the dormant species, for both $\mathrm{X}=\mathrm{I}$ (in ITP) and xanthate (in RAFT) that forms after $\mathrm{H}-\mathrm{H}$ monomer addition (PVDF-CF $-\mathrm{CH}_{2}-\mathrm{X}$ or $\left.\mathrm{PVDF}_{\mathrm{T}}-\mathrm{X}\right) .{ }^{24}$ Consequently, the $\mathrm{PVDF}_{\mathrm{T}}-\mathrm{X}$ dormant species are less easily reactivated, accumulate in the system during the polymerization, and lead to a loss of control after relatively low degrees of polymerization. Since the transfer constants of alkyl iodides are lower than those of RAFT agents, $\mathrm{PVDF}_{\mathrm{T}} \mathrm{X}$ are trapped at a slower rate in ITP than in RAFT. In consequence, slightly longer PVDF chains can be obtained before the loss of control using ITP. However, these chains will have a larger number of intrachain inversions. Asandei et al. ${ }^{26}$ have demonstrated that the less reactive $\mathrm{PVDF}_{\mathrm{T}}-\mathrm{I}$ chains obtained by ITP could be reactivated using $\mathrm{Mn}_{2}(\mathrm{CO})_{10}$ and a photo irradiation process, and were able to synthesize block copolymers with longer PVDF block lengths. In this case, the second block was not controlled since it was synthesized under conventional radical polymerization conditions.

The third method deals with OMRP, in which a transition-metal complex reversibly traps the propagating polymer radicals. ${ }^{27,} 28$ This strategy has been successfully employed for the radical (co)polymerization of less reactive monomers, including vinyl acetate (VAc) ${ }^{27-30}$ and VAc-ethylene, ${ }^{31}$-2-methylene-1,3-dioxepane, ${ }^{32}$-methyl- 
acrylate $^{33}$ with $\mathrm{Co}^{\mathrm{II}}(\mathrm{acac})_{2} \quad($ acac $=$ acetylacetonate $)$ or $\operatorname{bis}(2-$ formylphenolato)cobalt(II) ${ }^{34}$ as controlling agent. We have recently reported the first OMRP of VDF under mild experimental conditions, using $\left[\mathrm{R}_{0}(\mathrm{VAc})_{\sim 4} \mathrm{Co}^{\mathrm{III}}(\mathrm{acac})_{2}\right]$ as initiator $\left(\mathrm{R}_{0}=\right.$ primary radical generated by $\left.\mathrm{V}-70\right) .{ }^{24}$ These polymerizations produced PVDFs with higher molar masses $\left(M_{n}=5,900\right.$ to $\left.14,500 \mathrm{~g} / \mathrm{mol}\right)$ and lower dispersities $(\nexists \leq 1.32)$ than those achieved by ITP or RAFT under the same conditions, because both the regular $\mathrm{PVDF}_{\mathrm{H}}-\mathrm{Co}^{\mathrm{III}}(\mathrm{acac})_{2}$ and the minor $\mathrm{PVDF}_{\mathrm{T}}-\mathrm{Co}^{\mathrm{III}}(\mathrm{acac})_{2}$ polymers have similar bond strengths, as indicated by a DFT study, ${ }^{24}$ and can be efficiently reactivated. However, this method required the rather cumbersome synthesis of the organometallic $\left[\mathrm{R}_{0}(\mathrm{VAc})_{\sim 4} \mathrm{Co}^{\mathrm{III}}(\mathrm{acac})_{2}\right]$ initiator. This was a strong incentive for the search of a more convenient initiating system for the $\mathrm{Co}^{\mathrm{II}}(\mathrm{acac})_{2}$-mediated polymerization of VDF based on commercially available $\left[\mathrm{Co}^{\mathrm{II}}(\mathrm{acac})_{2}\right]$ and a conventional radical initiator.

This contribution reports a screening of various initiating systems, culminating with the identification of suitable conditions for controlling the radical homopolymerization of VDF. Furthermore, additional macromolecular engineering is described, beyond the single example provided in our earlier report, ${ }^{24}$ using the in situ generated PVDF$\mathrm{Co}(\mathrm{acac})_{2}$ macroinitiator to prepare well-defined PVAc and PVDF-containing diblock copolymers.

\section{Experimental}

\section{Materials}

1,1-Difluoroethylene (VDF) was kindly provided from Arkema (Pierre Benite, France). Bis(tert-butylcyclohexyl) peroxydicarbonate $\quad\left(\right.$ Perkadox $^{\circledR} 16, \quad \mathrm{P} 16,90 \%$, ) was purchased from AkzoNobel. Di-tert-butyl peroxide (DTBP, 98\%), benzoyl peroxide 
(BPO, 75\%), reagentPlus grade dimethyl carbonate (DMC, >99\%, Merk), Cobalt(II) acetylacetonate $\left(\mathrm{Co}(\mathrm{acac})_{2}, \quad 97 \%\right)$, vinyl acetate $(\mathrm{VAc}, \quad \geq 99 \%), \quad 2,2,6,6-$ tetramethylpiperidine 1-oxy (TEMPO, 98\%) and $n$-pentane (95\%) were purchased from Sigma Aldrich and used as received. Deuterated acetone (acetone- $\left.d_{6}\right)$ (purity>99.8\%) used for ${ }^{1} \mathrm{H}$ and ${ }^{19} \mathrm{~F}$ NMR spectroscopy was purchased from Euroiso-top (Grenoble, France).

\section{Characterizations}

\section{Nuclear Magnetic Resonance (NMR) Spectroscopy}

${ }^{1} \mathrm{H}$ and ${ }^{19} \mathrm{~F}$ NMR spectra were recorded on a Bruker AC 400 Spectrometer $(400 \mathrm{MHz}$ for ${ }^{1} \mathrm{H}$ and $376 \mathrm{MHz}$ for ${ }^{19} \mathrm{~F}$ ) using acetone- $d_{6}$ as solvent. The sample temperature was set to $298 \mathrm{~K}$. Chemical shifts and coupling constants are given in Hertz (Hz) and parts per million (ppm), respectively. The experimental conditions for recording the ${ }^{1} \mathrm{H}$ [or ${ }^{19} \mathrm{~F}$ ] NMR spectra were as follows: flip angle $90^{\circ}$ [or $30^{\circ}$, acquisition time $4.5 \mathrm{~s}$ [or $0.7 \mathrm{~s}$ ], pulse delay $2 \mathrm{~s}$ [or $5 \mathrm{~s}$ ], number of scans 32 [or 64], and a pulse width of $5 \mu$ s for ${ }^{19}$ F NMR.

\section{Gel permeation chromatography (GPC)}

The apparent number average molar masses and dispersities of the synthesized polymers were determined using a GPC system (Varian 390-LC) multi-detector equipped with a differential refractive index detector (RI), a light scattering (LS) and a viscosity detector using a guard column (Varian Polymer Laboratories PLGel 5 $\mu \mathrm{m}, 50$ x $7.5 \mathrm{~mm}$ ) and two ResiPore columns of the same type. The mobile phase was DMF with $0.1 \%$ wt $\mathrm{LiBr}$ adjusted at a flow rate of $1 \mathrm{~mL} \mathrm{~min}{ }^{-1}$ while the columns were thermostated at $70{ }^{\circ} \mathrm{C}$. The GPC system was calibrated using low dispersed poly(methyl 
methacrylate) (PMMA) standards ranging from 550 to $1,568,000 \mathrm{~g} \mathrm{~mol}^{-1}$ (EasiVialAgilent).

\section{OMRP of VDF initiated by P16 in the presence of $\mathrm{Co}(\mathrm{acac})_{2}$}

The polymerization of VDF (Entry 9, Table 2) was performed in a $50 \mathrm{~mL}$ Hastelloy autoclave Parr system (HC 276) equipped with a manometer, a mechanical Hastelloy anchor, a rupture disk (3000 PSI), inlet and outlet valves equipped with a special steel pipe, and a Parr electronic controller for stirring speed and heating control. A typical polymerization of VDF by OMRP mediated by $\mathrm{Co}(\mathrm{acac})_{2}$ was performed as follows. Initially, $\mathrm{Co}(\mathrm{acac})_{2}(0.40 \mathrm{~g}, 1.55 \mathrm{mmol})$ was introduced into the autoclave and then the reactor was closed and put under vacuum $\left(10^{-2}\right.$ mbar) in order to remove any residual traces of oxygen. Then, a degassed solution of DMC (30 mL) was transferred through a funnel tightly connected to the inlet valve of the autoclave. The reactor was then cooled in a liquid nitrogen bath, and VDF gas $(8.00 \mathrm{~g}, 0.124 \mathrm{~mol})$ was introduced under weight control. Subsequently, the autoclave was warmed up to room temperature and gradually heated to $60{ }^{\circ} \mathrm{C}$ while the reaction solution was mechanically stirred. A degassed solution of P16 (1.24 g, $3.11 \mathrm{mmol})$ in DMC (10 mL) was introduced in the reactor using an HPLC pump (5.0 $\mathrm{mL} / \mathrm{min})$. The polymerization was conducted for 24 $\mathrm{h}$ and then quenched by transferring (via using a HPLC pump) a nitrogen-purged solution of TEMPO (0.72 g, $4.66 \mathrm{mmol}, 3$ equivalents with respect to $\left.\mathrm{Co}(\mathrm{acac})_{2}\right)$ in DMC (5 mL) into the reactor and letting it react for $1 \mathrm{~h}$ at $60{ }^{\circ} \mathrm{C}$, according to a previously reported procedure. ${ }^{35}$ Finally, the autoclave was immersed in an iced bath and, after depressurization by venting, opened to air. The purified product was obtained after two repeated precipitations in 10 -fold excess $(400 \mathrm{~mL})$ of chilled pentane and it was recovered by centrifugation followed by drying under vacuum overnight. The final 
product was recovered as a brown powder $(2.17 \mathrm{~g}, 28 \%$ yield $)$ and characterized by ${ }^{1} \mathrm{H}$ and ${ }^{19} \mathrm{~F}$ NMR spectroscopy and gel permeation chromatography. It should be stressed that the polymerization yield was assumed identical to the monomer conversion, since it is particularly difficult to experimentally determine the VDF conversion.

${ }^{1} \mathrm{H}$ NMR (400 MHZ, acetone- $\mathrm{d}_{6}, \delta(\mathrm{ppm})$, Figure 3$) \delta(\mathrm{ppm}): 0.85-0.89\left(\left(\mathrm{C}_{3}\right)_{3}-\mathrm{C}-\right.$ of P16 fragment), 1.16-1.20 (- $\underline{\mathrm{CH}}_{3}$ TEMPO)), 1.26-1.87 (- $\underline{\mathrm{C}}_{2}$ of P16 fragment and TEMPO), 2.38-2.40 ((- $\left.\mathrm{CF}_{2}-\underline{\mathrm{C}}_{2}-\mathrm{C}_{2}-\mathrm{CF}_{2}-\right)$, reverse VDF-VDF T-T addition and ($\left.\mathrm{CF}_{2}-\underline{\mathrm{CH}}_{2}-\underline{\mathrm{C}}_{2}-\mathrm{CF}_{2}-\mathrm{TEMPO}\right)$ ), 2.70-3.10 (- $\underline{\mathrm{H}}_{2}-\mathrm{CF}_{2}-\mathrm{C}_{2}-\mathrm{CF}_{2}$, normal VDF-VDF H$\mathrm{T}$ addition and (- $\left.\mathrm{CH}_{2}-\mathrm{CF}_{2}-\mathrm{C}_{2}-\mathrm{CF}_{2}-\mathrm{TEMPO}\right), 3.70\left(\mathrm{CH}_{3}-\mathrm{O}-(\mathrm{C}=\mathrm{O})-\mathrm{O}-\mathrm{CH}_{2}-\mathrm{CH}_{2}-\mathrm{CF}_{2}-\right.$ ), $4.30\left(\mathrm{CH}_{3}-\mathrm{O}-(\mathrm{C}=\mathrm{O})-\mathrm{O}-\mathrm{C}_{2}-\mathrm{CH}_{2}-\mathrm{CF}_{2}-\right), 4.54$ ((tert-butyl-cyclo-hexyl-O- $(\mathrm{C}=\mathrm{O})-\mathrm{O}-$ $\left.\mathrm{C}_{2}-\mathrm{CF}_{2}\right)$, and $\left.\left(-\mathrm{CH}_{2}-\mathrm{CF}_{2}-\mathrm{CF}_{2}-\mathrm{CH}_{2}-\mathrm{TEMPO}\right)\right), 4.88-4.94\left(-\mathrm{CH}_{2}-\mathrm{CF}_{2}-\mathrm{C} \underline{\mathrm{H}}=\mathrm{CF}_{2}\right)$.

${ }^{19} \mathrm{~F}$ NMR (400 MHZ, acetone- $\mathrm{d}_{6}, \delta(\mathrm{ppm})$, Figure 4): -62.4 $\left(-\mathrm{CH}_{2}-\mathrm{CF}_{2}-\mathrm{CH}_{2}-\mathrm{CF}_{2}-\right.$ TEMPO), -68.0 (- $\left.\mathrm{CF}_{2}-\mathrm{CH}_{2}-\mathrm{CH}_{2}-\mathrm{CF}_{2}-\mathrm{TEMPO}\right),-73.6$ (- $\left.\mathrm{CH}_{2}-\mathrm{CF}_{2}-\mathrm{CF}_{2}-\mathrm{CH}_{2}-\mathrm{TEMPO}\right)$, 85.9 (- $\left.\mathrm{CH}_{2}-\mathrm{CF}_{2}-\mathrm{CH}_{2}-\mathrm{CF}_{2}-\mathrm{TEMPO}\right),-92.1\left(\left(-\mathrm{CH}_{2}-\mathrm{CF}_{2}-\mathrm{CH}_{2}-\mathrm{CF}_{2}\right)\right.$ normal VDF-VDF H$\mathrm{T}$ addition), -92.7 (- $\left.\mathrm{CF}_{2}-\mathrm{CH}_{2}-\mathrm{CH}_{2}-\mathrm{CF}_{2}-\mathrm{CH}_{2}-\mathrm{CF}_{2}-\mathrm{CH}_{2}-\mathrm{CF}_{2}-\right),-92.8\left(\mathrm{CH}_{2}-\mathrm{CF}_{2}-\mathrm{CH}_{2}-\right.$ $\left.\mathrm{CF}_{2}-\mathrm{H}\right),-93.2\left(\mathrm{CH}_{3}-\mathrm{O}-(\mathrm{C}=\mathrm{O})-\mathrm{O}-\mathrm{CH}_{2}-\mathrm{CH}_{2}-\mathrm{CF}_{2}-\mathrm{CH}_{2}\right)-95.8\left(-\mathrm{CF}_{2}-\mathrm{CH}_{2}-\mathrm{CH}_{2}-\mathrm{CF}_{2}-\mathrm{CH}_{2}-\right.$ ), -103.5 tert-butyl-cyclo-hexyl-O-(C=O)-O- $\mathrm{CH}_{2}-\mathrm{CF}_{2}{ }^{-},-108.1$ to $-108.5\left(\mathrm{CH}_{2}-\mathrm{CF}_{2}-\right.$ $\left.\mathrm{CF}_{2}-\mathrm{CH}_{3}\right),-114.4\left(\mathrm{CH}_{2}-\mathrm{CF}_{2}-\mathrm{CF}_{2}-\mathrm{CH}_{2}\right)$ reverse VDF-VDF $\mathrm{H}-\mathrm{H}$ addition, $-116.7\left(\mathrm{CH}_{2}-\right.$ $\left.\mathrm{CF}_{2}-\mathrm{CF}_{2}-\mathrm{CH}_{2}-\right),-114.7$ to $-115.8\left(-\mathrm{CH}_{2}-\mathrm{CF}_{2}-\mathrm{CF}_{2}-\mathrm{CH}_{3}\right),-115.4\left(-\mathrm{CH}_{2}-\mathrm{CF}_{2}-\mathrm{CH}_{2}-\mathrm{CF}_{2}-\right.$ $\mathrm{H}),-116.9\left(-\mathrm{CH}_{2}-\mathrm{CF}_{2}-\mathrm{CF}_{2}-\mathrm{CH}_{2}-\mathrm{CH}_{2}-\mathrm{CF}_{2}-\mathrm{H}\right)$.

\section{Kinetics Study of the VDF OMRP initiated by Co(acac)2/P16}

The general procedure was similar to that described in detail above. A series of polymerizations were carried out for the $\mathrm{Co}(\mathrm{acac})_{2}$-mediated OMRP of VDF targeting a constant molar ratio of $[\mathrm{VDF}]_{0} /\left[\mathrm{Co}(\mathrm{acac})_{2}\right]_{0}=80$ keeping the molar ratio of initiator 
to cobalt mediator constant $\left([\mathrm{P} 16] /\left[\mathrm{Co}(\mathrm{acac})_{2}\right]=2 / 1\right)$. The polymerizations were quenched by a nitrogen purged TEMPO solution at different polymerization times $(0.25$ $\mathrm{h}$ to $24 \mathrm{~h}$ ) and the polymerization yield was determined by gravimetry following the aforementioned procedure. The evolution of the number average molar masses as a function of conversion was monitored by GPC (Figure 2a).

\section{Synthesis of PVDF- $b$-PVAc diblock copolymers}

A typical procedure for the synthesis of PVDF- $b$-PVAc diblock copolymers was performed as follows: the OMRP of VDF mediated by $\mathrm{Co}(\mathrm{acac})_{2}$ in the presence of P16 $\left([\mathrm{VDF}]_{0} /[\mathrm{P} 16]_{0} /\left[\mathrm{Co}(\mathrm{acac})_{2}\right]_{0}=80 / 2 / 1\right)$ at $60{ }^{\circ} \mathrm{C}$ was set up using the procedure described above. The polymerization was allowed to proceed for $1 \mathrm{~h}$, then an aliquot was withdrawn from the reaction medium through a special steel pipe adapted on the outlet valve and quenched with a nitrogen purged TEMPO solution in DMC. The aliquot was precipitated in chilled pentane, dried in high vacuum and analyzed by GPC. Subsequently, the autoclave was slowly depressurized so as to remove the unreacted VDF. Afterwards a solution of degassed VAc $(10.7 \mathrm{~mL}, 0.116 \mathrm{~mol})$ was transferred in the autoclave using an HPLC pump $(5.0 \mathrm{~mL} / \mathrm{min})$ and the polymerization was continued for $18 \mathrm{~h}$ at $60{ }^{\circ} \mathrm{C}$. The polymerization was quenched by introducing a TEMPO solution in the autoclave $\left(0.72 \mathrm{~g}, 4.66 \mathrm{mmol}, 3\right.$ equivalents with respect to $\mathrm{Co}(\mathrm{acac})_{2}$ in DMC (5 $\mathrm{mL})$ ) using the aforementioned procedure and left to react for $1 \mathrm{~h}$ at $40{ }^{\circ} \mathrm{C}$. Finally, the autoclave was immersed in an iced bath and opened to air. The purified product (brown powder) was obtained after two repeated precipitations in 10-fold excess $(500 \mathrm{~mL})$ of chilled pentane and recovered by centrifugation followed by drying under vacuum overnight and characterized by ${ }^{1} \mathrm{H}$ and ${ }^{19} \mathrm{~F}$ NMR spectroscopy and GPC. In total, three 
PVDF- $b$-PVAc diblock copolymers were synthesized by varying the ratio of VAc to PVDF-Co(acac) 2 macroinitiator (Entries 1-3, Table 5).

${ }^{1} \mathrm{H}$ NMR (400 MHZ, acetone- $\mathrm{d}_{6}, \delta$ (ppm), Figure 7): 0.87-0.97 ( $\underline{\mathrm{H}}_{3} \mathrm{P} 16$ fragment), 1.16-1.45 (- $\underline{\mathrm{CH}}_{3},-\mathrm{CH}_{2}-\underline{\mathrm{C}}_{2}-\mathrm{CH}_{2}-$ and $-\underline{\mathrm{C}}_{2}-\mathrm{CH}_{2}-\underline{\mathrm{C}}_{2}-$ of TEMPO and $\underline{\mathrm{C}}_{2}$ of P16

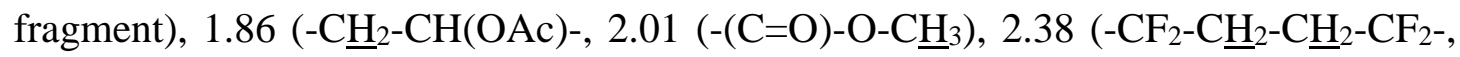
VDF-VDF T-T reverse addition), 2.80-3.10 (- $\underline{\mathrm{C}}_{2}-\mathrm{CF}_{2}-\underline{\mathrm{C}}_{2}-\mathrm{CF}_{2}$, , regular VDF-VDF H-T addition), 4.51 (-C-C프-O-(C=O)-O- $\left.\mathrm{CH}_{2}-\mathrm{CF}_{2}-\right), 4.95\left(-\mathrm{CH}_{2}-\mathrm{C} \underline{\mathrm{H}}-(\mathrm{OAc})-\mathrm{CH}_{3}\right), 5.25$ (- $\left.\mathrm{CH}_{2}-\mathrm{CF}_{2}-\mathrm{CH}_{2}-\mathrm{C} \underline{\mathrm{H}}-(\mathrm{OAc}) \mathrm{dyad}\right)$.

\section{Results and discussion}

\section{Effect of initiator on the VDF OMRP}

Previous studies from our group indicated that azo-initiators are not suitable for the radical (co)polymerization of VDF, whereas peroxide initiators perform well. ${ }^{36}$ Thus, three different types of peroxide initiators were tested for the polymerization of VDF via OMRP in the presence of $\mathrm{Co}(\mathrm{acac})_{2}$, namely bis(tert-butylcyclohexyl) peroxydicarbonate (P16), di-tert butyl peroxide (DTBP) and benzoyl peroxide (BPO) (molecular structures are presented in Scheme S1). In preliminary explorations, all initiators were separately tested at $[\text { initiator }]_{0} /\left[\mathrm{Co}(\mathrm{acac})_{2}\right]_{0}$ molar ratios of $0.5 / 1$ and $1 / 1$ at $30{ }^{\circ} \mathrm{C}$ using the same $[\mathrm{VDF}]_{0} /\left[\mathrm{Co}(\mathrm{acac})_{2}\right]_{0}$ ratio. Because the $\mathrm{Co}(\mathrm{acac})_{2}$-mediated radical polymerization method is known to be sensitive to oxygen, ${ }^{37}$ polymerizations were performed out under protective atmosphere. However, this RDRP is tolerant to residual water since it has also been performed successfully in aqueous media. ${ }^{38,39}$ All the polymerizations were carried out in dimethyl carbonate (DMC), a good solvent for PVDF that also exhibits fast rate of VDF polymerization. ${ }^{26}$ As shown by the results reported in Table 1, the use of BPO and DTBP met with limited or no success. DTBP 
did not lead to any polymerization whereas BPO gave a very low monomer conversion after $48 \mathrm{~h}$.

On the other hand, P16 presented slightly higher conversions for shorter polymerization times (24 h). Therefore, P16 was chosen as the initiator for further optimization. The reasons for the lower efficiency of DTBP and BPO are currently unknown and are the topic of current stoichiometric investigations.

Table 1. Results for the VDF polymerization in DMC initiated by DTBP, BPO and P16 in the presence of $\mathrm{Co}(\mathrm{acac})_{2} .{ }^{\mathrm{a}}$

\begin{tabular}{|c|c|c|c|c|c|}
\hline Initiator & {$[\text { Initiator }]_{0} /\left[\mathrm{Co}(\mathrm{acac})_{2}\right]_{0}$} & $\begin{array}{l}\text { Polymer. } \\
\text { time (h) }\end{array}$ & Conv. $(\%)^{\mathrm{b}}$ & $M_{n}(\mathrm{~g} / \mathrm{mol})^{\mathrm{c}}$ & $Ð$ \\
\hline \multirow{2}{*}{ DTBP } & $0.5 / 1$ & 48 & 0 & - & - \\
\hline & $1 / 1$ & 48 & 0 & - & - \\
\hline \multirow{2}{*}{ BPO } & $0.5 / 1$ & 48 & 2.5 & 2,000 & 1.15 \\
\hline & $1 / 1$ & 48 & 2.5 & 2,200 & 1.18 \\
\hline \multirow{2}{*}{ P16 } & $0.5 / 1$ & 24 & 7.0 & 2,100 & 1.16 \\
\hline & $1 / 1$ & 24 & 5.0 & 1,500 & 1.13 \\
\hline
\end{tabular}

\section{Effect of the $[\mathrm{P16}]_{0} /\left[\mathrm{Co}(\mathrm{acac})_{2}\right]_{0}$ ratio on the VDF OMRP}

The $[\mathrm{P} 16]_{0} /\left[\mathrm{Co}(\mathrm{acac})_{2}\right]_{0}$ molar ratio was varied in the $0.5 / 1$ to $2 / 1$ range at polymerization temperatures of 30 and $60{ }^{\circ} \mathrm{C}$ (Scheme 1, Table 2). For the sake of comparison, a conventional radical polymerization of VDF at $60{ }^{\circ} \mathrm{C}$ was also performed (Entry 1, Table 2). 


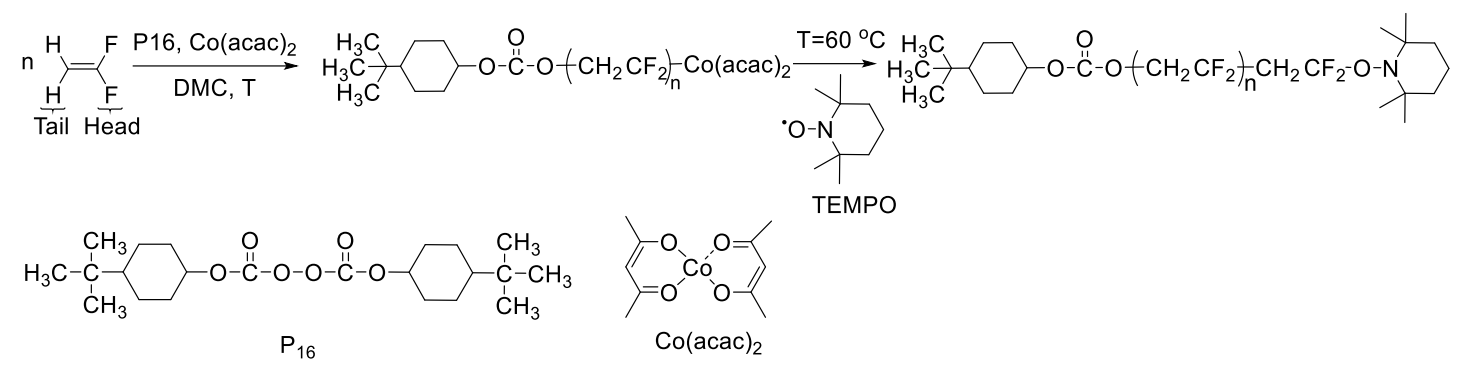

Scheme 1. Preparation of PVDF by OMRP mediated by $\mathrm{Co}(\mathrm{acac})_{2}$ initiated by bis(tert-butylcyclohexyl) peroxydicarbonate (P16).

Increasing the [initiator $] /\left[\mathrm{Co}(\mathrm{acac})_{2}\right]$ ratio from 0.5 to 1.5 or the temperature of polymerization from $30^{\circ} \mathrm{C}$ to $60{ }^{\circ} \mathrm{C}$ (for this range of [initiator] $/\left[\mathrm{Co}(\mathrm{acac})_{2}\right]$ ratios) had a negligible effect on the number average molar masses and did not increase monomer conversion which only reached a few percent in each case. Increasing both the initial [initiator] $] /\left[\mathrm{Co}(\mathrm{acac})_{2}\right]$ ratio to $2 / 1$ and the polymerization temperature to $60{ }^{\circ} \mathrm{C}$ (Entry 9, Table 2) led to a notable increment of the conversion (from 5-7\% to $27 \%$ ), while the dispersity also slightly increased but remained acceptably low $(\nexists \leq 1.35)$.

Table 2. Experimental conditions and results for the VDF polymerization in DMC initiated by $\mathrm{P} 16$ in the presence of $\mathrm{Co}(\mathrm{acac})_{2}{ }^{\mathrm{a}}$

\begin{tabular}{cccccc}
\hline Entry & {$[\mathrm{P} 16]_{0} /\left[\mathrm{Co}(\mathrm{acac})_{2}\right]_{0}$} & $\mathrm{~T}\left({ }^{\mathrm{o}} \mathrm{C}\right)$ & $\mathrm{Conv}(\%)^{\mathrm{b}}$ & $M_{n}(\mathrm{~g} / \mathrm{mol})^{\mathrm{c}}$ & $Ð$ \\
\hline $1^{\mathrm{d}}$ & $1 / 0$ & 60 & 75 & 5,600 & 1.73 \\
2 & $0.5 / 1$ & 30 & 7 & 2,100 & 1.16 \\
3 & $0.5 / 1$ & 60 & 6 & 2,000 & 1.14 \\
4 & $1 / 1$ & 30 & 5 & 1,500 & 1.13 \\
5 & $1 / 1$ & 60 & 6 & 1,800 & 1.12 \\
6 & $1.5 / 1$ & 30 & 5 & 2,800 & 1.15 \\
7 & $1.5 / 1$ & 60 & 15 & 5,800 & 1.28 \\
8 & $2 / 1$ & 30 & 11 & 2,800 & 1.15 \\
9 & $2 / 1$ & 60 & 27 & 7,600 & 1.35 \\
\hline
\end{tabular}


Reaction conditions: ${ }^{a}[\mathrm{VDF}]=3.13 \mathrm{~mol} / \mathrm{L},[\mathrm{VDF}]_{0} /\left[\mathrm{Co}(\mathrm{acac})_{2}\right]_{0}=80$ for $24 \mathrm{~h}$. The P16 initiator amount was adjusted at constant $\mathrm{Co}(\mathrm{acac})_{2}$ concentration. ${ }^{\mathrm{b}}$ The VDF conversion was calculated gravimetrically. ${ }^{\mathrm{c}}$ GPC DMF-LiBr, calibrated using PMMA standards. ${ }^{\mathrm{d}}[\mathrm{VDF}] /[\mathrm{P} 16]=40$

The higher temperature led to a faster polymerization, as expected from the displacement of the moderating OMRP equilibrium and from the increase of the polymerization rate constant $\left(\mathrm{k}_{\mathrm{p}}\right)$. The conventional polymerization of VDF initiated by P16 without any $\mathrm{Co}(\mathrm{acac})_{2}$ (Entry 1, Table 2) led to higher conversion but the resulting PVDF also had a higher dispersity $(Đ=1.73)$ compared to the polymerizations carried out in the presence of $\mathrm{Co}(\mathrm{acac})_{2}(\Theta=1.16-1.35)$. The above results suggest that $\mathrm{Co}(\mathrm{acac})_{2}$ can serve as an efficient controlling agent.

We suppose that the combined action of the peroxycarbonate and $\mathrm{Co}(\mathrm{acac})_{2}$ rapidly generates radicals by a redox process, as reported previously for $\mathrm{Co}(\mathrm{acac})_{2} /$ peroxides systems including $\mathrm{BPO} / \mathrm{Co}(\mathrm{acac})_{2}$-initiated $\mathrm{OMRP}$ of vinyl acetate. ${ }^{40,41}$ In principle, in the case of a $100 \%$ initiator efficiency (generating carboxyl radicals), a second equivalent of $\mathrm{Co}(\mathrm{acac})_{2}$ is necessary to play the role of moderator of the polymer chains generated from the carboxyl radical. ${ }^{42}$ This means that the ideal theoretical initial [peroxide] $/\left[\mathrm{Co}(\mathrm{acac})_{2}\right]$ molar ratio is 0.5 for a controlling mechanism by reversible termination. In the presence of excess radicals the polymerization likely proceeds via degenerative transfer. The optimal ratio would depend on the relative rates of the redox process, of the additions of the carboxyl radicals to the monomer, of the propagation step, of the polymer chain trapping process, and of the subsequent thermal decomposition of any residual peroxide and is thus expected to be initiator- and monomer-dependent. For instance, the best results for the $[\mathrm{BPO}] /\left[\mathrm{Co}(\mathrm{acac})_{2}\right]$-initiated OMRP of VAc was achieved with a $[\mathrm{BPO}] /\left[\mathrm{Co}(\mathrm{acac})_{2}\right]$ ratio of $1 / 1.3 .{ }^{41}$ Further investigations into the intimate details of the initiation mechanism are ongoing in our laboratories and will be reported in due course. 


\section{Effect of the $[\mathrm{VDF}]_{0} /\left[\mathrm{Co}(\mathrm{acac})_{2}\right]_{0}$ molar ratio}

All the subsequent investigations were carried out with the optimized $[\mathrm{P} 16]_{0} /\left[\mathrm{Co}(\mathrm{acac})_{2}\right]_{0}$ molar ratio of $2 / 1$. A linear dependence of the PVDF molar mass on the $[\mathrm{VDF}]_{0} /\left[\mathrm{Co}(\mathrm{acac})_{2}\right]_{0}$ molar ratio would constitute a solid evidence that $\mathrm{Co}(\mathrm{acac})_{2}$ plays an efficient role as a controlling agent. ${ }^{43}$ Therefore, a series of polymerizations was conducted at different $[\mathrm{VDF}]_{0} /\left[\mathrm{Co}(\mathrm{acac})_{2}\right]_{0}$ molar ratios while maintaining the $[\mathrm{P} 16]_{0} /\left[\mathrm{Co}(\mathrm{acac})_{2}\right]_{0}$ constant (Table 3).

Table 3. Experimental conditions and results of the VDF OMRP for a series of $[\mathrm{VDF}]_{0} /\left[\mathrm{Co}(\mathrm{acac})_{2}\right]_{0}$ molar ratios at $60^{\circ} \mathrm{C}$.

\begin{tabular}{ccccc}
\hline Entry & {$[\mathrm{VDF}]_{0} /\left[\mathrm{Co}(\mathrm{acac})_{2}\right]_{0}$} & Conversion $(\%)^{\mathrm{a}}$ & $M_{n}(\mathrm{~g} / \mathrm{mol})^{\mathrm{b}}$ & $Ð$ \\
\hline 1 & 20 & 25 & 1,400 & 1.10 \\
2 & 40 & 25 & 3,700 & 1.15 \\
3 & 60 & 25 & 6,100 & 1.28 \\
5 & 80 & 27 & 7,600 & 1.32 \\
6 & 110 & 22 & 8,500 & 1.31 \\
7 & 130 & 22 & 9,000 & 1.30 \\
\hline
\end{tabular}
Reactions conditions: $[\mathrm{VDF}]_{0}=3.13 \mathrm{~mol} / \mathrm{L},[\mathrm{P} 16]_{0} /\left[\mathrm{Co}(\mathrm{acac})_{2}\right]_{0}=2 /$
gravimetrically. ${ }^{\mathrm{b}} \mathrm{GPC} \mathrm{DMF}-\mathrm{LiBr}$, calibrated using PMMA standards.

All polymerizations reached about $25 \%$ of monomer conversion after $18 \mathrm{~h}$ in spite of the variation of the VDF/initiator and the VDF/cobalt ratio which should lead to different polymerization rates. This suggests that the polymerizations stopped after few hours which is consistent with the half-life of P16 $\left(\sim 1.76 \mathrm{~h}\right.$ at $\left.60{ }^{\circ} \mathrm{C}\right)$. Indeed, the latter is most probably exhausted before $18 \mathrm{~h}$ (about $96 \%$ consumption of P16 after $8 \mathrm{~h}$ ) and cannot generate radicals needed to maintain the DT mechanism leading to the 
premature stop of the polymerization. This assumption is confirmed by the evolution of the monomer conversion with time (vide infra). As expected, these polymerizations produced PVDF with molar masses that increase with the $[\mathrm{VDF}]_{0} /\left[\mathrm{Co}(\mathrm{acac})_{2}\right]_{0}$ ratio $\left(M_{n}=1,400-9,300 \mathrm{~g} / \mathrm{mol}\right)$ accompanied with relatively low dispersities $(1.10 \leq \emptyset \leq$ 1.35) (Figure 1b). Nevertheless, at higher initial ratios (>80) the molar mass was no longer increased linearly. Instead, $M_{\mathrm{n}}$ reached a maximum value $(9,300 \mathrm{~g} / \mathrm{mol})$, with only marginal increase of dispersity. Furthermore, the GPC traces of the synthesized PVDFs (Figure 1a) displayed unimodal distributions showing no sign of coupling reactions. ${ }^{44,45}$ A tentative explanation for this behavior is that high molar mass $\left(M_{n}\right.$ $>7,000 \mathrm{~g} / \mathrm{mol}$ ) PVDF chains become less soluble in DMC at $60{ }^{\circ} \mathrm{C}$, which in turn leads to retardation and termination of polymerization. This hypothesis could also explain the negligible increase of dispersity after PVDF reached ca. 7,000 g/mol, suggesting that the polymer-solvent interactions become less favorable, therefore minimizing the chain transfer reactions. In order to verify our assumption, PVDF homopolymers of molar masses 3,700 and 9,300 g/mol (Entries 2 and 7, Table 3) were fully dissolved in DMC at room temperature. Subsequently, the polymers solutions were gradually heated up at $60{ }^{\circ} \mathrm{C}$. Remarkably, after 5 minutes the high molar mass PVDF was precipitated while the low molar mass PVDF remained completely dissolved (Figure S1).

a)

b) 

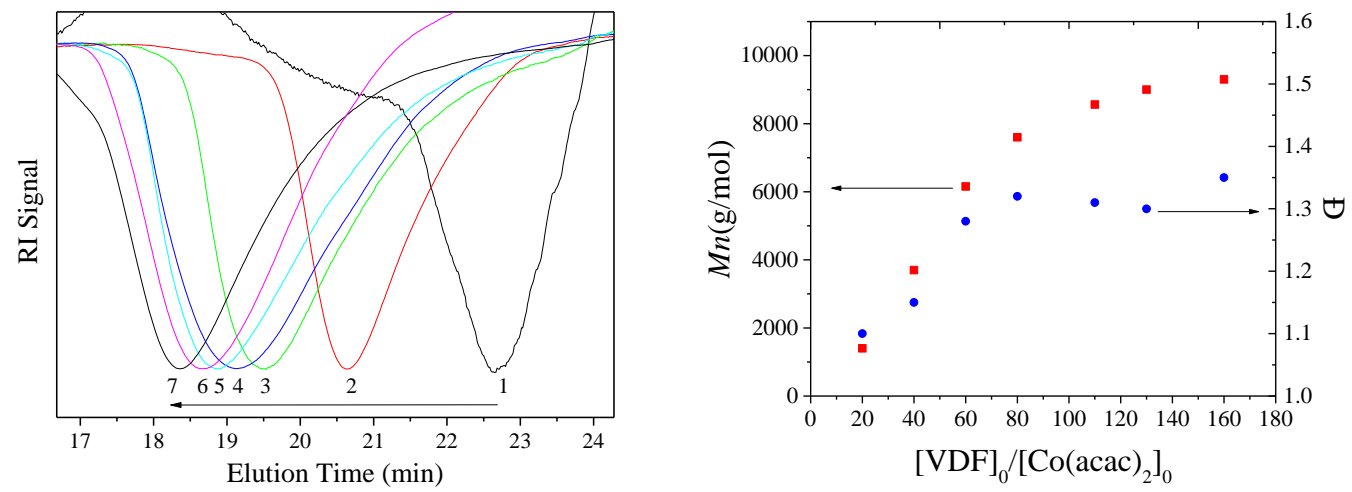

Figure 1. (a) Evolutions of the GPC traces and (b) plot of $M_{n}$ and $Ð v s$ $[\mathrm{VDF}]_{0} /\left[\mathrm{Co}(\mathrm{acac})_{2}\right]_{0}$ for the OMRP of VDF Conditions: $[\mathrm{P} 16]_{0} /\left[\mathrm{Co}(\mathrm{acac})_{2}\right]_{0}=2 / 1, \mathrm{~T}=$ $60{ }^{\circ} \mathrm{C}$.

\section{Kinetics on the OMRP VDF polymerization}

A kinetic study was carried out through a series of a single point experiments (ranging from $0.25 \mathrm{~h}$ to $16 \mathrm{~h}$ ). All polymerizations were conducted under similar conditions, $\left([\mathrm{VDF}]_{0} /[\mathrm{P} 16]_{0} /\left[\mathrm{Co}(\mathrm{acac})_{2}\right]_{0}=80 / 2 / 1\right.$ at $60{ }^{\circ} \mathrm{C}$ in $\mathrm{DMC}$ and were monitored by ${ }^{19} \mathrm{~F} \mathrm{NMR}$ (Figure S2) and GPC measurements. The GPC traces of the synthesized PVDFs displayed unimodal distributions which significantly shifted toward lower elution times (Figure S3). Figure 2a illustrates the evolution of $M_{n}$ and $Ð$ versus monomer conversion (Entries 1-9, Table S1) where the linear relationship between molar mass and conversion indicates that the chain growth is indeed controlled. In addition, the dispersity gradually increased but remained low $(1.01<\bigoplus<1.24)$ throughout the polymerization. The kinetic plot (Figure $2 b$ ) exhibited three different regimes. Initially, a fast polymerization was observed without any sign of induction period in contrast with the RAFT polymerization of VDF. ${ }^{15}$ This behavior is expected for a redox initiating system. ${ }^{39,41,46}$ The polymerization proceeded at a fast rate for $1 \mathrm{~h}$, then it slowly decreased until it terminated after $8 \mathrm{~h}$ (see the plateau from 8 to $16 \mathrm{~h}$ on Figure 2b) where the conversion reached $27 \%$. It is strongly believed that the change of polymerization rate after $2 \mathrm{~h}$ (which corresponds to $M_{n}=7,000-8,000 \mathrm{~g} / \mathrm{mol}$ ) is due to 
limited solubility of PVDF in DMC at $60^{\circ} \mathrm{C}$, as mentioned above (Figure S1). The same behavior was observed in our previously reported study, which made use of the oligo(VAc)-cobalt(III) initiator, where a change of slope for the kinetic plot was also noticed in the same molar mass regime. ${ }^{24}$

a)

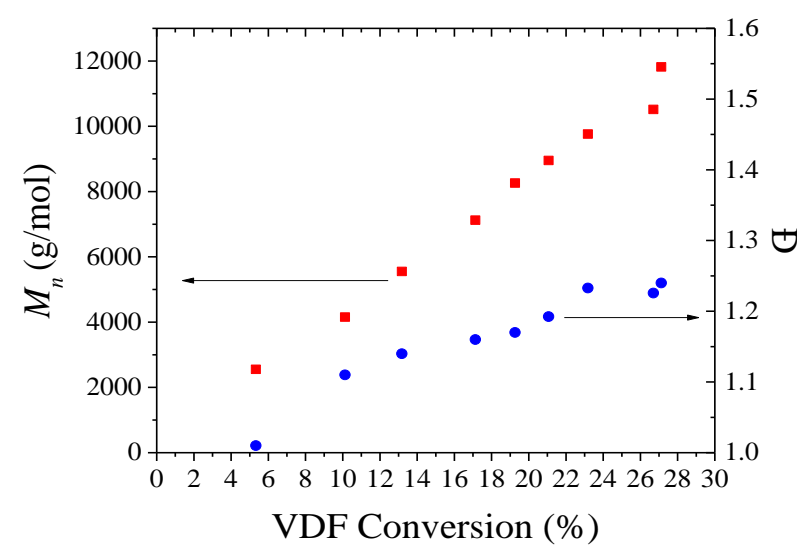

b)

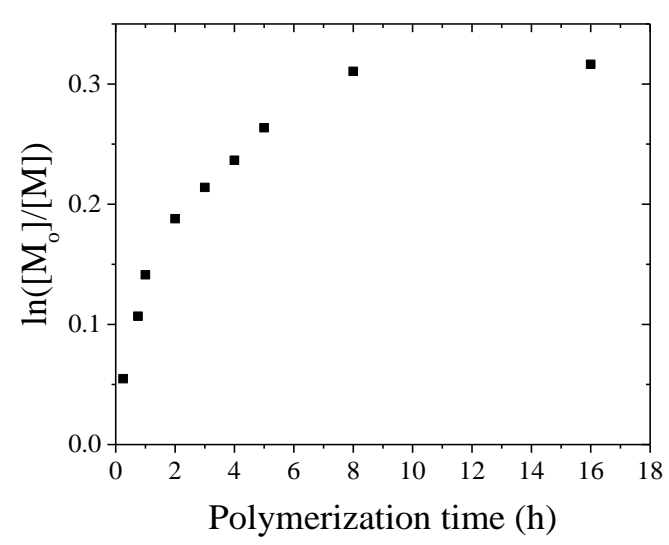

Figure 2. Plots of a) evolution of $M_{n}$ and $Ð$ vs the monomer conversion and b) $\ln \left([\mathrm{M}]_{0} /[\mathrm{M}]\right)$ vs polymerization time for the VDF homopolymerization via OMRP. Conditions: $[\mathrm{VDF}]_{0} /[\mathrm{P} 16]_{0} /\left[\mathrm{Co}(\mathrm{acac})_{2}\right]_{0}=80 / 2 / 1, \mathrm{~T}=60{ }^{\circ} \mathrm{C}$.

However, two notable differences between the two polymerization strategies are the polymerization rates and the conversions. The polymerization rates are higher when the $[\mathrm{P} 16] /\left[\mathrm{Co}(\mathrm{acac})_{2}\right]$ initiating system was used, probably because the polymerization occurs within the degenerative transfer regime, and because of the higher temperature used in this experiment ( $v s .40^{\circ} \mathrm{C}$ when using the oligo(VAc)-cobalt(III) initiator). ${ }^{47,} 48$ On the other hand, significantly greater conversions (54\%) could be achieved in the latter case. Concerning the inverted monomer additions, both methods gave similar results. Specifically, the H-H additions increased gradually with VDF conversion reaching a maximum of ca. $4 \%$, as monitored from ${ }^{19} \mathrm{~F}$ NMR and calculated using 
equation S1 (Figure S4). Further evidence of RDRP was shown by chain extension (vide infra).

\section{NMR Spectroscopy of PVDF formed by OMRP}

By means of $1 \mathrm{D}{ }^{1} \mathrm{H},{ }^{19} \mathrm{~F}$, and 2D Hetero-COSY ${ }^{1} \mathrm{H}-{ }^{19} \mathrm{~F}$ NMR experiments and based on previously reported studies, it was possible to thoroughly characterize the PVDF synthesized by OMRP after quenching with TEMPO and purification. According to the literature, TEMPO plays the role of radical scavenger by displacing the covalently bonded $\mathrm{Co}(\mathrm{acac})_{2}$ moiety from the propagating PVDF active chains and thus preventing unfavorable chain terminations. ${ }^{43}$

To clearly identify the PVDF microstructure and the TEMPO chain ends, a lowmolar mass PVDF (Entry 1, Table 3) was selected. Figure 3 exhibits the ${ }^{1} \mathrm{H}$ NMR spectrum including the assignment of all resonances. The broad resonance appearing at 2.70-3.10 pm is assigned to the characteristic head-to-tail $-\mathrm{CH}_{2}-\mathrm{CF}_{2}-\mathrm{CH}_{2}-\mathrm{CF}_{2}-\mathrm{VDF}-$ VDF dyads, whereas the sharper and more resolved resonances in the $2.38-2.40 \mathrm{ppm}$ range are assigned to the tail-to-tail $-\mathrm{CF}_{2}-\underline{\mathrm{C}}_{2}-\mathrm{CH}_{2}-\mathrm{CF}_{2}$ - dyads, in agreement with previous studies. ${ }^{15,17,24}$

The end groups arising from the initiator fragment of P16 $\left(\mathrm{C}_{3}\right)_{3} \mathrm{C}-$ and $\mathrm{C}_{2}$ protons are highlighted by signals at 0.85 and $0.89 \mathrm{ppm}$ and in the $1.16-1.20 \mathrm{ppm}$ range, respectively. Additionally, this regime might contains $\mathrm{P} 16$ fragments of $\left(\mathrm{CH}_{3}\right)_{3} \mathrm{C}$ - and $\mathrm{C}_{2}$ derived from decarboxylation of the initiator. ${ }^{49-51}$ The resonances centered at 1.16$1.20 \mathrm{ppm}$ and several other signals in the $1.26-1.89 \mathrm{ppm}$ range are attributed to the $\mathrm{C}_{3}, \quad-\mathrm{C}-\left(\mathrm{CH}_{3}\right)_{2}-\mathrm{CH}_{2}-\underline{\mathrm{C}}_{2}-\mathrm{CH}_{2}-\mathrm{C}-\left(\mathrm{CH}_{3}\right)_{2}$ and $-\mathrm{C}-\left(\mathrm{CH}_{3}\right)_{2}-\mathrm{C}_{2}-\mathrm{CH}_{2}-\underline{\mathrm{C}}_{2}-\mathrm{C}-\left(\mathrm{CH}_{3}\right)_{2}$ protons of the TEMPO-end groups. 


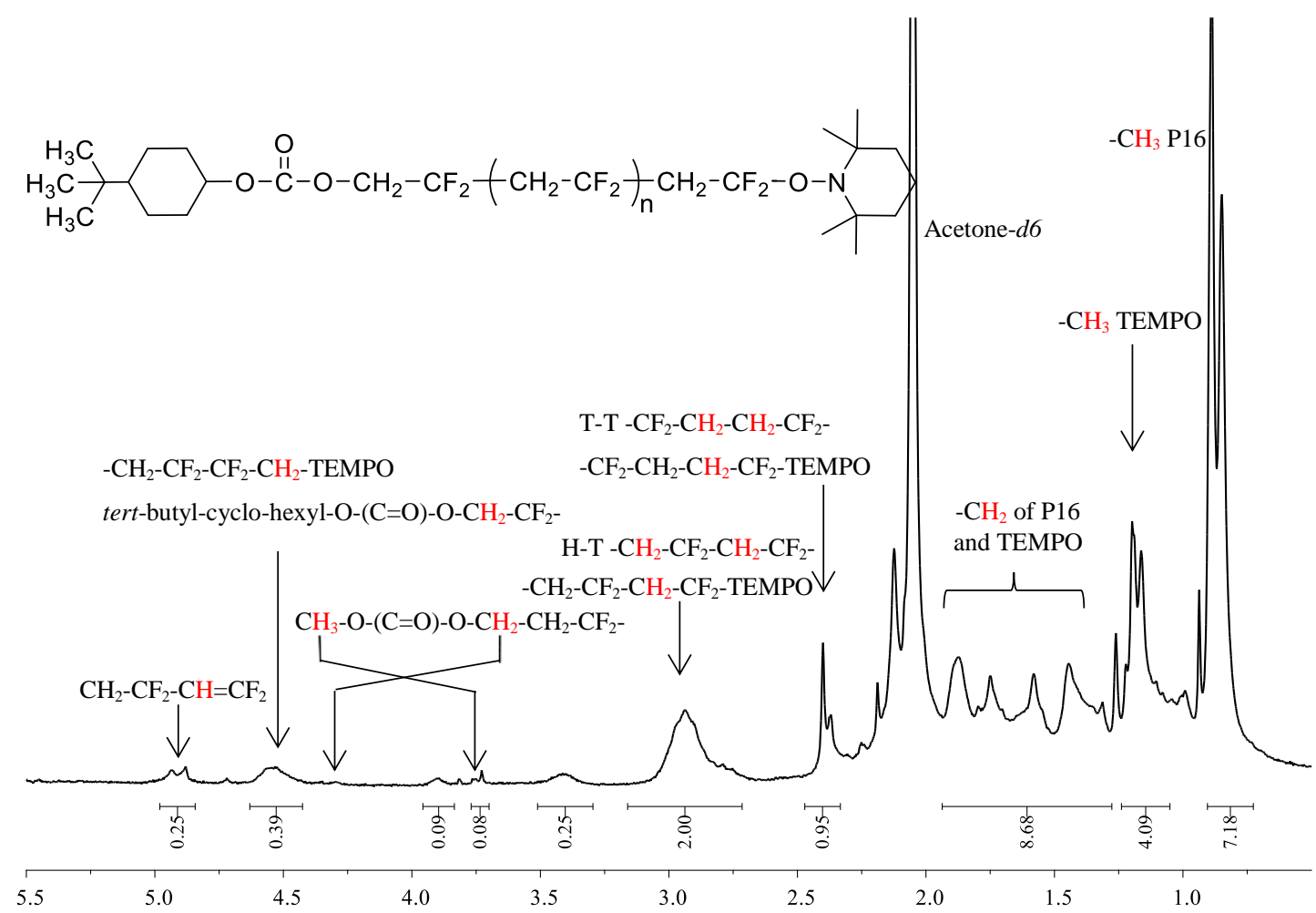

Figure 3. $\quad{ }^{1} \mathrm{H}$ NMR spectrum recorded in $\left(\mathrm{CD}_{3}\right)_{2} \mathrm{CO}$ of a low molar mass PVDF homopolymer synthesized via OMRP (Entry 1, Table 3).

The broad resonance in the 4.40 to $4.60 \mathrm{ppm}$ range represents the overlap of the tertbutyl-cyclo-hexyl-O-(C=O)-O- $\underline{\mathrm{H}}_{2}-\mathrm{CF}_{2}$ moiety of the $\mathrm{P} 16$ fragments connected to the first VDF unit and the $-\mathrm{CH}_{2}-\mathrm{CF}_{2}-\mathrm{CF}_{2}-\underline{\mathrm{C}}_{2}-\mathrm{TEMPO}$ moiety corresponding to the $\omega$ chain end obtained after an inverted monomer addition. ${ }^{26,31}$ The resonances of the regular $\mathrm{CH}_{2}-\mathrm{CF}_{2}-\mathrm{CH}_{2}-\mathrm{CF}_{2}-\mathrm{TEMPO}$ and $\mathrm{T}-\mathrm{T}$ reverse addition $\mathrm{CF}_{2}-\mathrm{CH}_{2}-\mathrm{CH}_{2}-\mathrm{CF}_{2}-$ TEMPO chain ends overlap with the mid-chain H-T and T-T resonances at 2.94 and $2.40 \mathrm{ppm}$, as proven by the ${ }^{1} \mathrm{H}-{ }^{19} \mathrm{~F}$ Hetero-COSY analysis (vide infra). The resonances centered 3.70 and $4.30 \mathrm{ppm}$ are assigned at $3 \mathrm{H}$ and $2 \mathrm{H}$ respectively of $\mathrm{C}_{3}-\mathrm{O}-(\mathrm{C}=\mathrm{O})-$ O- $\underline{\mathrm{H}}_{2}-\mathrm{CH}_{2}-\mathrm{CF}_{2}-$ moiety produced after chain transfer to a DCM molecule and reinitiation by radical addition onto the $\mathrm{CH}_{2}$ site of $\mathrm{VDF}^{3}{ }^{3}$ The complex peak at 4.85-4.98 ppm might correspond to $-\mathrm{CH}_{2}-\mathrm{CF}_{2}-\mathrm{C} \underline{\mathrm{H}}=\mathrm{CF}_{2}$ chain-end unsaturation, generated by $\mathrm{H}$ transfer from the terminal H-T VDF unit. ${ }^{26,52}$ The latter assignment is supported by the 
absence of this peak in the ${ }^{1} \mathrm{H}$ NMR spectrum of PVDF synthesized by conventional radical polymerization (Figure S5), which also indicates that the resonance does not result from bimolecular disproportionation. A tentative mechanism generating this function is metal-catalyzed chain transfer (CCT) to monomer. ${ }^{53}$ Indeed, although CCT is common for more activated monomers such as methacrylates and styrenics, its possible intervention for a less activated monomers (vinyl acetate) has also been recently pointed out for a cobalt complex analogous to $\mathrm{Co}(\mathrm{acac})_{2} .{ }^{54}$

Figure 4 illustrates the ${ }^{19} \mathrm{~F}$ NMR spectrum of the same sample, which exhibits the expected intense signal at $-92.1 \mathrm{ppm}$ attributed to the $-\mathrm{CH}_{2}-\mathrm{CF}_{2}-\mathrm{CH}_{2}-\mathrm{CF}_{2}-$ dyads formed by the normal H-T addition. ${ }^{24-26}$ The resonances at -114.4 and -116.7 ppm are indicative of the chain defects caused by $\mathrm{H}-\mathrm{H}$ reverse additions ${ }^{24-26}$ and those at -95.8 and $-92.7 \mathrm{ppm}$ correspond to the regular $\mathrm{CF}_{2}$ moieties adjacent to these reverse additions. The peak at $-92.8 \mathrm{ppm}$ is assigned to $-\mathrm{CH}_{2}-\mathrm{CF}_{2}-\mathrm{CH}_{2}-\mathrm{CF}_{2}-\mathrm{H}$ while the doublet of multiplets ranging from $-114.9 \mathrm{ppm}$ to $-115.4 \mathrm{ppm}$ and the peaks centered at -116.9 ppm are assigned to the $-\underline{\mathrm{CF}}_{2}-\mathrm{H}$ chain-ends caused by hydrogen atom abstraction (chain transfer to solvent, monomer or polymer). The analogous transfer for the minor PVDF$\mathrm{CF}_{2}-\mathrm{CH}_{2}{ }^{\cdot}\left(\mathrm{PVDF}_{\mathrm{T}}{ }^{\circ}\right)$ radical obtained by $\mathrm{H}-\mathrm{H}$ addition leads to the resonance centered at $-108.1 \mathrm{ppm}$ and -115.1 and assigned to $\mathrm{CH}_{2}-\mathrm{CF}_{2}-\mathrm{CF}_{2}-\mathrm{CH}_{3}$ and $\mathrm{CH}_{2}-\mathrm{CF}_{2}-\mathrm{CF}_{2}-\mathrm{CH}_{3}$, respectively (See Figure S6). Another resonance related to this transfer is observed at 93.2 ppm, corresponding to the $\mathrm{CH}_{3}-\mathrm{O}-\mathrm{C}(=\mathrm{O})-\mathrm{O}-\mathrm{CH}_{2}-\mathrm{CH}_{2}-\mathrm{CF}_{2}-\mathrm{CH}_{2}-$ moiety generated by the DMC radical initiation of a new chain. The resonance at $-103.5 \mathrm{ppm}$ is attributed to the first VDF dyad next to P16 fragment tert-butyl-cyclo-hexyl-O$(\mathrm{C}=\mathrm{O})-\mathrm{O}-\mathrm{CH}_{2}-\mathrm{CF}_{2}-$. Additionally, the ${ }^{19} \mathrm{~F}$ NMR spectrum reveals the presence of low field peaks located between -88 and $-64 \mathrm{ppm}$ and associated to the ultimate and penultimate VDF units connected to the TEMPO end-group, as observed in a previous 
study. ${ }^{24}$ These signals are not observed in the ${ }^{19} \mathrm{~F}$ NMR spectrum of the PVDF synthesized by conventional radical polymerization (Entry 1, Table 1, Figure S7), for which no TEMPO quenching of the dormant chain was carried out.

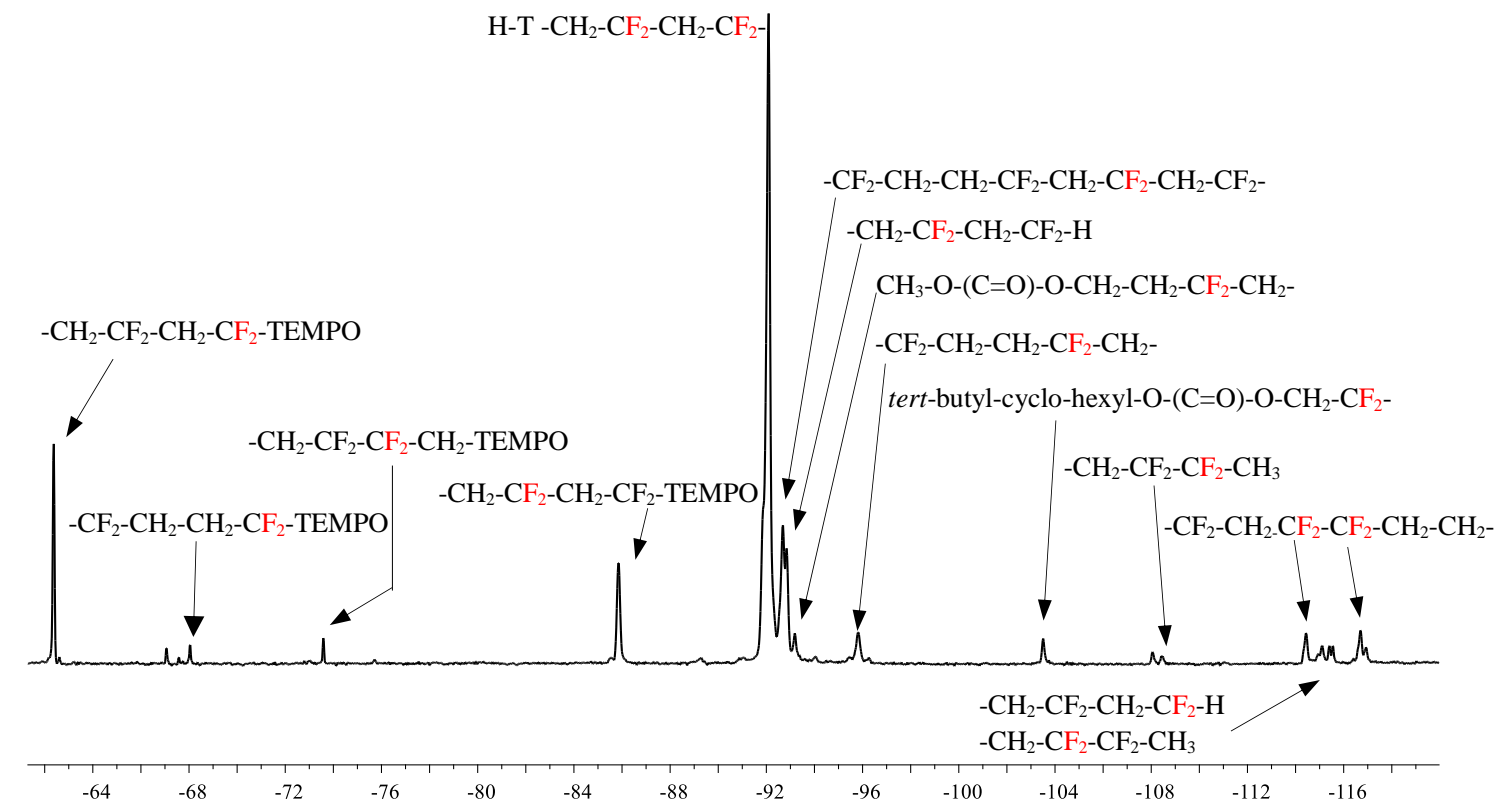

Figure 4. ${ }^{19} \mathrm{~F}$ NMR spectrum in $\left(\mathrm{CD}_{3}\right)_{2} \mathrm{CO}$ of a low molar mass PVDF homopolymer synthesized via OMRP (Entry 1, Table 3).

However, the $1 \mathrm{D}{ }^{1} \mathrm{H}$ and ${ }^{19} \mathrm{~F}$ NMR spectra were not sufficient for the identification of all resonances. The unambiguous assignment was made possible by a $2 \mathrm{D}{ }^{1} \mathrm{H}_{-}{ }^{19} \mathrm{~F}$ Hetero-COSY analysis (Figure 5, Figure S8 (enlarged graph)). 


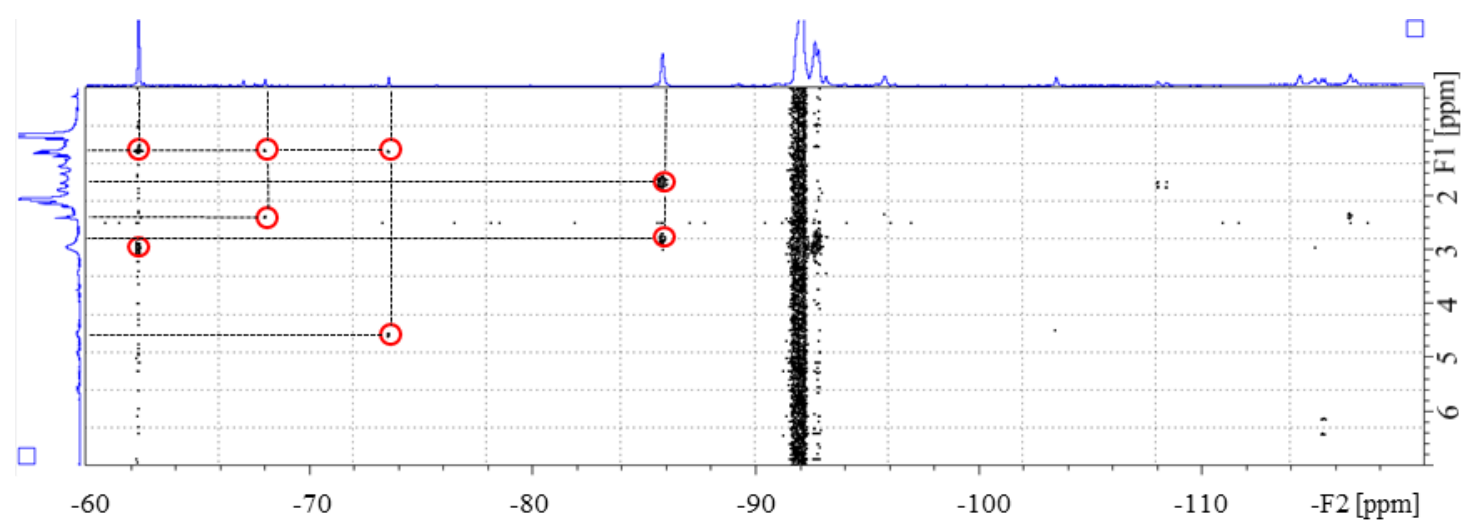

Figure 5. $\quad{ }^{1} \mathrm{H}_{-}{ }^{19} \mathrm{~F}$ Hetero-COSY spectrum of PVDF (Entry 1, Table 3) in $\left(\mathrm{CD}_{3}\right)_{2} \mathrm{CO}$. Vertical axis: ${ }^{1} \mathrm{H}$ NMR spectrum; horizontal axis: ${ }^{19} \mathrm{~F}$ NMR spectrum.

In particular, the $1.16 \mathrm{ppm}{ }^{1} \mathrm{H}$ NMR resonances of the $-\underline{\mathrm{C}}_{3}$ of TEMPO are clearly correlated with the ${ }^{19} \mathrm{~F}$ NMR resonance at $-62.4 \mathrm{ppm}$ (stronger signal), and with smaller resonances at -68.0 and $-73.6 \mathrm{ppm}$ of similar relatively weak intensity. The stronger ${ }^{19} \mathrm{~F}$ NMR resonance at $-62.4 \mathrm{ppm}$ is in turn correlated with the normal $\mathrm{H}-\mathrm{T}$ resonance at $2.94 \mathrm{ppm}$ and is thus assigned to $\mathrm{CH}_{2}-\mathrm{CF}_{2}-\mathrm{CH}_{2}-\mathrm{CF}_{2}-\mathrm{TEMPO}$, whereas the smaller and similar intensity ${ }^{19} \mathrm{~F}$ NMR resonances at -68.0 and $-73.6 \mathrm{ppm}$ correlate, respectively, with the resonance at $2.40 \mathrm{ppm}$, which is very close to the T-T dyad resonance and is therefore interpreted as the resonance of $-\mathrm{CF}_{2}-\mathrm{CH}_{2}-\mathrm{C}_{2}-\mathrm{CF}_{2}-\mathrm{TEMPO}$, and with the one at $4.57 \mathrm{ppm}$, which is assigned to $-\mathrm{CH}_{2}-\mathrm{CF}_{2}-\mathrm{CF}_{2}-\mathrm{C}_{2}-\mathrm{TEMPO}$.

Table 4. ${ }^{19}$ F NMR chemical shifts and assignments of a low molar mass PVDF homopolymer synthesized via OMRP (Entry 1, Table 3).

\begin{tabular}{|c|c|}
\hline Designation & Chemical shift (ppm) \\
\hline$-\mathrm{CH}_{2}-\mathrm{CF}_{2}-\mathrm{CH}_{2}-\mathrm{CF}_{2}-\mathrm{TEMPO}$ & -62.4 \\
\hline$-\mathrm{CF}_{2}-\mathrm{CH}_{2}-\mathrm{CH}_{2}-\mathrm{CF}_{2}-\mathrm{TEMPO}$ & -68.0 \\
\hline$-\mathrm{CH}_{2}-\mathrm{CF}_{2}-\mathrm{CF}_{2}-\mathrm{CH}_{2}-\mathrm{TEMPO}$ & -73.6 \\
\hline$-\mathrm{CH}_{2}-\mathrm{CF}_{2}-\mathrm{CH}_{2}-\mathrm{CF}_{2}-\mathrm{TEMPO}$ & -85.9 \\
\hline$-\mathrm{CH}_{2}-\mathrm{CF}_{2}-\mathrm{CH}_{2}-\mathrm{CF}_{2}-$ & -92.1 \\
\hline
\end{tabular}




\begin{tabular}{|c|c|}
\hline$-\mathrm{CF}_{2}-\mathrm{CH}_{2}-\mathrm{CH}_{2}-\mathrm{CF}_{2}-\mathrm{CH}_{2}-\mathrm{CF}_{2}-\mathrm{CH}_{2}-\mathrm{CF}_{2}-$ & -92.7 \\
\hline$-\mathrm{CH}_{2}-\mathrm{CF}_{2}-\mathrm{CH}_{2}-\mathrm{CF}_{2}-\mathrm{H}$ & -92.8 \\
\hline $\mathrm{CH}_{3}-\mathrm{O}-(\mathrm{C}=\mathrm{O})-\mathrm{O}-\mathrm{CH}_{2}-\mathrm{CH}_{2}-\mathrm{CF}_{2}-\mathrm{CH}_{2}-$ & -93.2 \\
\hline$-\mathrm{CF}_{2}-\mathrm{CH}_{2}-\mathrm{CH}_{2}-\mathrm{CF}_{2}-\mathrm{CH}_{2}-$ & -95.8 \\
\hline tert-butyl-cyclo-hexyl-O- $(\mathrm{C}=\mathrm{O})-\mathrm{O}-\mathrm{CH}_{2}-\mathrm{CF}_{2}-$ & -103.5 \\
\hline$-\mathrm{CH}_{2}-\mathrm{CF}_{2}-\mathrm{CF}_{2}-\mathrm{CH}_{3}$ & -108.1 \\
\hline$-\mathrm{CF}_{2}-\mathrm{CH}_{2}-\mathrm{CF}_{2}-\mathrm{CF}_{2}-\mathrm{CH}_{2}-\mathrm{CH}_{2}-$ & $-114.4 \&-116.7$ \\
\hline$-\mathrm{CH}_{2}-\mathrm{CF}_{2}-\mathrm{CF}_{2}-\mathrm{CH}_{3}$ & -115.1 \\
\hline$-\mathrm{CH}_{2}-\mathrm{CF}_{2}-\mathrm{CH}_{2}-\mathrm{CF}_{2}-\mathrm{H}_{2}$ & -115.4 \\
\hline$-\mathrm{CH}_{2}-\mathrm{CF}_{2}-\mathrm{CF}_{2}-\mathrm{CH}_{2}-\mathrm{CH}_{2}-\mathrm{CF}_{2}-\mathrm{H}$ & -116.9 \\
\hline
\end{tabular}

Hence, the ${ }^{19} \mathrm{~F}$ NMR resonance at $-68.0 \mathrm{ppm}$ is attributed to $-\mathrm{CH}_{2}-\mathrm{CH}_{2}-\mathrm{CH}_{2}-\mathrm{CF}_{2}-$ TEMPO and that at $-73.6 \mathrm{ppm}$ is assigned to $-\mathrm{CH}_{2}-\mathrm{CF}_{2}-\mathrm{CF}_{2}-\mathrm{CH}_{2}-\mathrm{TEMPO}$. Finally, the ${ }^{19} \mathrm{~F}$ resonance at $-85.9 \mathrm{ppm}$ is correlated with the ${ }^{1} \mathrm{H}$ resonances at $2.94 \mathrm{ppm}$ and at ca. $1.80 \mathrm{ppm}$ (area of the TEMPO-end groups). Therefore, these resonance are attributed to the $-\mathrm{CH}_{2}-\mathrm{CF}_{2}-\mathrm{CH}_{2}-\mathrm{CF}_{2}-\mathrm{TEMPO}$ moiety. All the aforementioned assignments are summarized in Table 4.

The assignment of the peak centered at $-67.1 \mathrm{ppm}$ remains undefined since there is no clear indication either from ${ }^{1} \mathrm{H}-{ }^{19} \mathrm{~F}$ Hetero-COSY spectrum or from the literature. Additionally, it should be stressed that this peak is also present in the ${ }^{19} \mathrm{~F}$ NMR spectrum of PVDF synthesized by conventional polymerization (Figure S7). A previous study reported by our team wrongly assigned this peak to the $-\mathrm{CF}_{2}-\mathrm{CH}_{2}-\mathrm{CH}_{2}-\mathrm{CF}_{2}-$ TEMPO moiety. ${ }^{24}$

\section{Synthesis of the PVDF- $b$-PVAc diblock copolymers}

To check the "living" character of PVDF-Co(acac $)_{2}$ chains synthesized using the $\mathrm{P} 16 / \mathrm{Co}(\mathrm{acac})_{2}$ initiating system, sequential polymerizations of VAc were examined (Scheme 2). PVDF- $b$-PVAc block copolymers have been previously synthesized by our 
group via RAFT and OMRP. ${ }^{24,} 25$ The latter method proved versatile, producing polymers that are end capped by the metal complex in which the labile carbon-metal bond at the chain end can be reactivated for further functionalization such as cobaltmediated radical coupling to obtain symmetric ABA triblock copolymers. ${ }^{31}$ Furthermore, to explore the limitations of the PVDF chain extension with VAc, block copolymers containing PVAc segment of various lengths were prepared, under identical experimental conditions, by varying the of VAc/macroinitiator molar ratio. The results of these syntheses are summarized in Table 5.

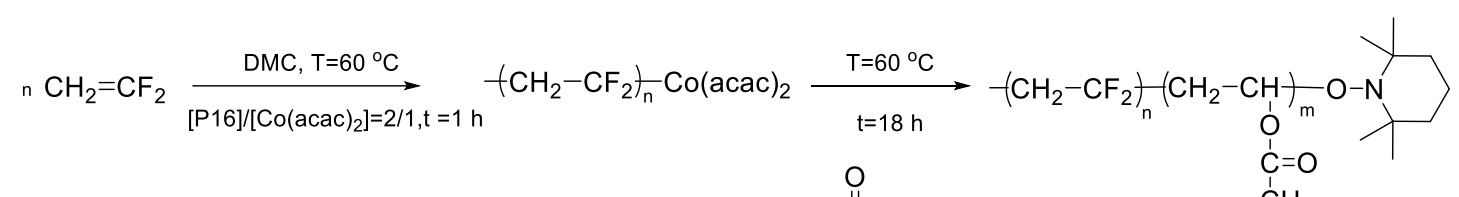

$$
\begin{aligned}
& \text { 1) } \overbrace{\substack{O \\
V A c}}^{O} \\
& \mathrm{CH}_{3} \\
& \text { 2) } \\
& \stackrel{1}{O-N}
\end{aligned}
$$

Scheme 2. Synthesis of the PVDF- $b$-PVAc diblock copolymers by sequential

\begin{tabular}{|c|c|c|c|c|c|c|c|}
\hline \multirow[b]{2}{*}{ Entry } & \multicolumn{2}{|c|}{ PVDF-Co(acac) ${ }_{2}^{a}$} & \multicolumn{2}{|c|}{ PVDF- $b$-PVAc ${ }^{b}$} & \multirow{2}{*}{$\begin{array}{l}\text { Theor. } \\
\text { VAc } \\
\text { content } \\
(\mathrm{mol} \%)^{\mathrm{c}}\end{array}$} & \multirow{2}{*}{$\begin{array}{c}\text { VAc } \\
\text { content } \\
(\mathrm{mol} \%)^{\mathrm{d}}\end{array}$} & \multirow{2}{*}{$\begin{array}{c}\text { VDF } \\
\text { content in } \\
\text { "PVAc } \\
\text { block" (mol } \\
\% \text { ) }\end{array}$} \\
\hline & $M_{n}(\mathrm{~g} / \mathrm{mol})$ & $\bigoplus$ & $M_{n}(\mathrm{~g} / \mathrm{mol})$ & $\oslash$ & & & \\
\hline 1 & 6,700 & 1.13 & 13,100 & 1.19 & 56 & 49 & 18 \\
\hline 2 & 6,000 & 1.16 & 21,000 & 1.28 & 80 & 75 & 9 \\
\hline 3 & 7,400 & 1.09 & 29,500 & 1.39 & 87 & 86 & 2 \\
\hline
\end{tabular}
OMRP.

Table 5. Molecular characteristics of the PVDF macroinitiators and of the three PVDF- $b$-PVAc block copolymers synthesized in situ via sequential OMRP.

${ }^{\text {a }}$ PVDF-Co $(\text { acac })_{2}$ was synthesized by OMRP at $[\mathrm{VDF}]_{0} /[\mathrm{P} 16]_{0} /\left[\mathrm{Co}(\mathrm{acac})_{2}\right]_{0}=80 / 2 / 1$ at $60{ }^{\circ} \mathrm{C}$ for $1 \mathrm{~h}^{\mathrm{b}} \mathrm{Chain}$ extension of PVDF$\mathrm{Co}(\mathrm{acac})_{2}$ with VAc was performed at $60^{\circ} \mathrm{C}$ after venting VDF off, ${ }^{\mathrm{c}}$ Theoretical VAc composition ${ }^{\mathrm{d}}$ Experimental VAc composition calculated by ${ }^{1} \mathrm{H}$ NMR spectroscopy, ${ }^{\mathrm{e}}$ VDF composition which was randomly copolymerized along the "PVAc block". 
Figure 6 displays the GPC chromatograms of the PVDF macroinitiators and of three final PVDF- $b$-PVAc block copolymers. The PVDF macroinitiators exhibited similar molecular characteristics while after chain extension, the GPC traces shifted towards lower elution times. Additionally, no residual trace of the starting PVDF macroinitiator was detected when superimposing the VDF-Co(acac $)_{2}$ and the derived block copolymer traces, suggesting a successful block copolymerization (although RI detection may not be optimum to assess residual PVDF chains in the presence of PVAc). The number average molar masses increased proportionally to the [VAc]/[PVDF] ratio, from 13,100 to $29,500 \mathrm{~g} / \mathrm{mol}$, while the theoretical and experimental VAc compositions were found in reasonable agreement. The dispersities of the PVDF-Co(acac $)_{2}$ intermediates were low $(\bigoplus<1.16)$ and then slightly increased to greater values $(\bigoplus=1.19-1.39)$ for longer PVAc block lengths, which suggests the presence of irreversible chain terminations. The significant tailing observed in the GPC traces of the diblock copolymers confirms this hypothesis.

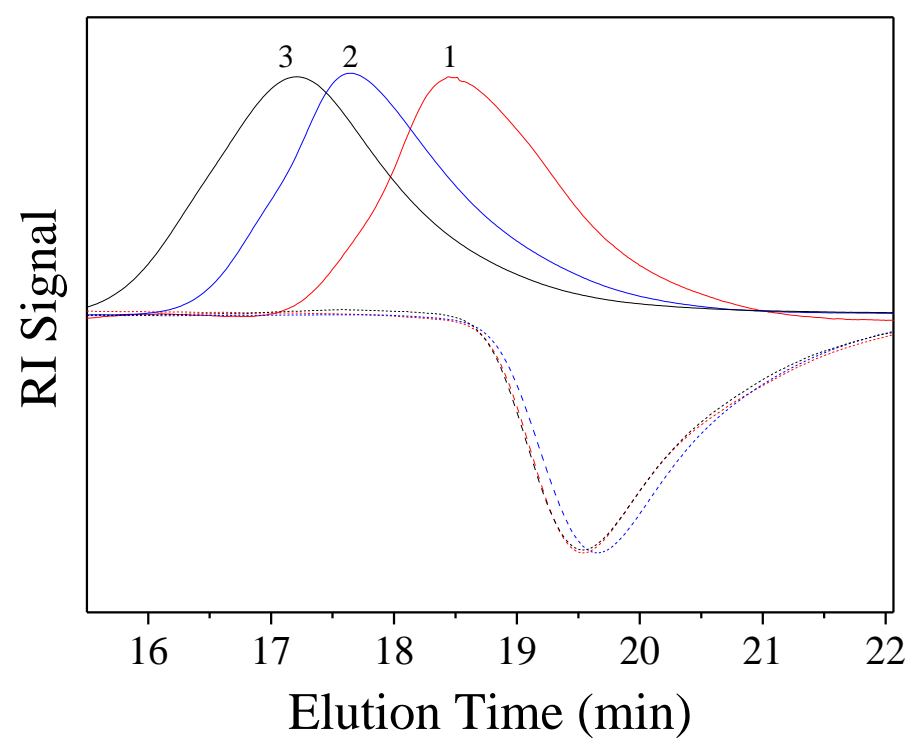

Figure 6. Normalized GPC traces of PVDF-Co(acac) 2 homopolymers (Entries 1 (--), 2 (--), 3 (--), Table 5) and PVDF-b-PVAc block copolymers formed by in situ sequential OMRP. 
The ${ }^{1} \mathrm{H}$ NMR analysis of the PVDF- $b$-PVAc diblock copolymers provided additional information (Figure 7). Resonances assigned to both PVDF and PVAc sequences were clearly observed. In particular, the ${ }^{1} \mathrm{H}$ NMR spectrum displays typical broad peaks centered at $1.86,2.01$, and 4.95 ppm corresponding to the $\underline{\mathrm{C}}_{2}, \mathrm{C}_{3}$ and $\mathrm{C} \underline{\mathrm{H}}$ of the PVAc block, respectively. In addition, a broad triplet at $2.97 \mathrm{ppm}$ is assigned to the $\underline{\mathrm{CH}}_{2}$ protons of the regular VDF H-T dyads and a broad peak at $2.38 \mathrm{ppm}$ is characteristic of the VDF T-T dyads, respectively. It should be underlined that residual VDF remained in the autoclave was copolymerized with VAc and was statistically incorporated in the new block $\left(\mathrm{r}_{\mathrm{VAc}}=1.67\right.$ and $\left.\mathrm{r}_{\mathrm{VDF}}=-0.40\right)$ as it was evidence by a broad peak centered at $5.25 \mathrm{ppm}$ which corresponds to the methyne group of the VAc units next to VDF monomers. ${ }^{55,56}$ The signals ranging from 1.16 to $1.45 \mathrm{ppm}$ are characteristic of the $\underline{\mathrm{C}}_{2}$ and $\underline{\mathrm{CH}}_{3}$ groups of TEMPO which overlap with those of $\underline{\mathrm{C}}_{2}$ fragment of P16. Finally, the peaks at 0.87 and 0.90 and $4.51 \mathrm{ppm}$ are assigned to the $\underline{\mathrm{C}}_{3}$ protons and $\mathrm{C} \underline{\mathrm{H}}$ of $\mathrm{P} 16$, respectively. Finally, it is worth to be mentioned that the ${ }^{19}$ F NMR spectrum of PVDF- $b$-PVAc block copolymer (Table 5, Entry 3, Figure S9) shows the absence of peaks in low field region attributed to PVDF-TEMPO chain end groups thus confirming the correct assignment of these groups. 

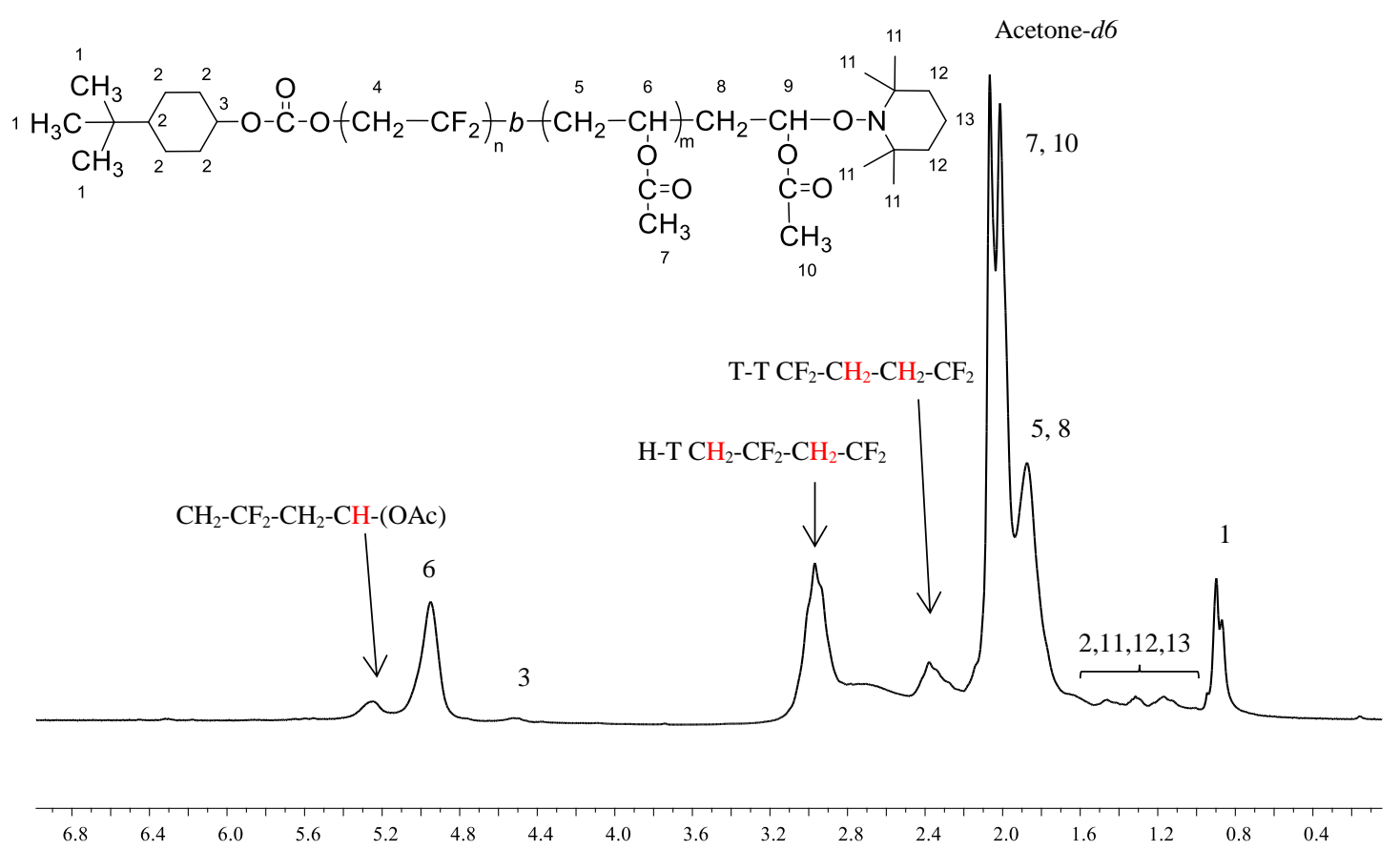

Figure 7. $\quad{ }^{1} \mathrm{H}$ NMR spectrum of a PVDF- $b$-PVAc block copolymer synthesized via sequential OMRP polymerization (Entry 1, Table 5) recorded in $\left(\mathrm{CD}_{3}\right)_{2} \mathrm{CO}$.

\section{Conclusions}

Previously, the Co(acac) $)_{2}$-mediated OMRP of VDF was effective only when oligo(VAc)-cobalt(III) was used as initiator. Nevertheless, the labor-intensive and timeconsuming synthesis of this initiator rendered this approach impractical. We have described here an alternative and straightforward strategy using a two componentinitiating system from commercially available compounds. Among various radical initiators, P16 was found to lead to acceptable control under optimized conditions $\left([\mathrm{P} 16]_{0} /\left[\mathrm{Co}(\operatorname{acac})_{2}\right]_{0}=2 / 1, \mathrm{~T}=60{ }^{\circ} \mathrm{C}\right)$, leading to PVDF homopolymers with low dispersities $(\bigoplus<1.35)$. However, PVDF homopolymers of high molar masses $\left(M_{n}>7,000 \mathrm{~g} / \mathrm{mol}\right)$ presented low solubility in DMC at $60{ }^{\circ} \mathrm{C}$ which in turn may have led to retardation and subsequently to the termination of polymerization, limiting the 
polymerization to low conversions (ca <27\%). 2D NMR studies of a low-molar-mass, TEMPO-quenched PVDF has allowed an in-depth analysis of the PVDF microstructure including the chain ends. Furthermore, low dispersed PVDF-Co(acac) $)_{2}$ polymers were used as macroinitiators for the in situ OMRP of VAc, yielding PVDF-co-PVAc block copolymers with unimodal and narrow molar mass distributions, confirming the livingness of this method and the high degree of chain-end functionality. Further optimization of this synthetic strategy might pave the way to industrially scalable processes for the straightforward synthesis of well-defined PVDF homopolymers and VDF-containing copolymers and block copolymers.

\section{References}

1. Améduri, B. From Vinylidene Fluoride (VDF) to the Applications of VDFContaining Polymers and Copolymers: Recent Developments and Future Trends. Chemical Reviews 2009, 109 (12), 6632-6686 DOI: 10.1021/cr800187m.

2. Smith, D. W.; Iacono, S. T.; Iyer, S. S., Handbook of Fluoropolymer Science and Technology. Wiley: New York, 2014.

3. Asandei, A. D. Photomediated Controlled Radical Polymerization and Block Copolymerization of Vinylidene Fluoride. Chemical Reviews 2016, 116 (4), 2244-2274 DOI: 10.1021/acs.chemrev.5b00539.

4. Améduri, B.; Sawada, H., Fluorinated Polymers: From Fundamental to Practical Synthesis and Applications. Volume 1: Synthesis, Properties, Processing and Simulations. Royal Society of Chemistry: Oxford, 2017.

5. Yang, L.; Li, X.; Allahyarov, E.; Taylor, P. L.; Zhang, Q. M.; Zhu, L. Novel polymer ferroelectric behavior via crystal isomorphism and the nanoconfinement $\begin{array}{llllll}\text { effect. } & \text { Polymer 2013, } 54 \text { (7), 1709-1728 DOI: }\end{array}$ http://dx.doi.org/10.1016/j.polymer.2013.01.035.

6. Soulestin, T.; Ladmiral, V.; Dos Santos, F. D.; Améduri, B. Vinylidene fluorideand trifluoroethylene-containing fluorinated electroactive copolymers. How does chemistry impact properties? Progress in Polymer Science 2017, 72, 16-60 DOI: https://doi.org/10.1016/j.progpolymsci.2017.04.004.

7. Cui, Z.; Drioli, E.; Lee, Y. M. Recent Progress in Fluoropolymers for Membranes. Prog. Polym. Sci. 2013, 39 (1), 164-198 DOI: http://dx.doi.org/10.1016/j.progpolymsci.2013.07.008.

8. Cardoso, V.; Correia, D.; Ribeiro, C.; Fernandes, M.; Lanceros-Méndez, S. Fluorinated Polymers as Smart Materials for Advanced Biomedical Applications. Polymers 2018, 10 (2), 161.

9. Mattern, D. E.; Lin, F. T.; Hercules, D. M. Laser Mass-Spectrometry of Poly(Fluoroethylenes). Anal Chem 1984, 56 (14), 2762-2769 DOI: Doi 10.1021/Ac00278a031. 
10. Cais, R. E.; Kometani, J. M. Polymerization of vinylidene fluoride-d2. Minimal regiosequence and branch defects and assignment of preferred chain-growth direction from the deuterium isotope effect. Macromolecules 1984, 17 (9), 1887-1889 DOI: 10.1021/ma00139a049.

11. Boschet, F.; Ameduri, B. (Co)polymers of Chlorotrifluoroethylene: Synthesis, Properties, and Applications. Chemical Reviews 2014, 114 (2), 927-980 DOI: $10.1021 / \mathrm{cr} 2002933$.

12. Tatemoto, M., Polymeric Materials Encyclopedia. Salamone, J. C., Ed. CRC Boca Raton: 1996; Vol. 5, pp 3847-3862.

13. Banerjee, S.; Patil, Y.; Ono, T.; Ameduri, B. Synthesis of $\omega$-Iodo and Telechelic Diiodo Vinylidene Fluoride-Based (Co)polymers by Iodine Transfer Polymerization Initiated by an Innovative Persistent Radical. Macromolecules 2017, 50 (1), 203-214 DOI: 10.1021/acs.macromol.6b02308.

14. Boyer, C.; Valade, D.; Sauguet, L.; Ameduri, B.; Boutevin, B. Iodine Transfer Polymerization (ITP) of Vinylidene Fluoride (VDF). Influence of the Defect of VDF Chaining on the Control of ITP. Macromolecules 2005, 38 (25), 10353-10362 DOI: 10.1021/ma051349f.

15. Guerre, M.; Campagne, B.; Gimello, O.; Parra, K.; Ameduri, B.; Ladmiral, V. Deeper Insight into the MADIX Polymerization of Vinylidene Fluoride. Macromolecules 2015, 48 (21), 7810-7822 DOI: 10.1021/acs.macromol.5b01528.

16. Banerjee, S.; Patil, Y.; Gimello, O.; Ameduri, B. Well-defined multiblock poly(vinylidene fluoride) and block copolymers thereof: a missing piece of the architecture puzzle. Chemical Communications 2017, 53 (79), 10910-10913 DOI: 10.1039/C7CC06122F.

17. Guerre, M.; Rahaman, S. M. W.; Améduri, B.; Poli, R.; Ladmiral, V. Limits of Vinylidene Fluoride RAFT Polymerization. Macromolecules 2016, 49 (15), 5386-5396 DOI: 10.1021/acs.macromol.6b01087.

18. Girard, E.; Marty, J.-D.; Ameduri, B.; Destarac, M. Direct Synthesis of Vinylidene Fluoride-Based Amphiphilic Diblock Copolymers by RAFT/MADIX Polymerization. ACS Macro Lett. 2012, 1 (2), 270-274 DOI: 10.1021/mz2001143.

19. Kostov, G.; Boschet, F.; Buller, J.; Badache, L.; Brandsadter, S.; Améduri, B. First Amphiphilic Poly(vinylidene fluoride-co-3,3,3-trifluoropropene)-b-oligo(vinyl alcohol) Block Copolymers as Potential Nonpersistent Fluorosurfactants from Radical Polymerization Controlled by Xanthate. Macromolecules 2011, 44 (7), 1841-1855 DOI: $10.1021 / \mathrm{ma102679f.}$

20. Liepins, R.; Surles, J. R.; Morosoff, N.; Stannett, V. T.; Timmons, M. L.; Wortman, J. J. Poly(vinylidene fluoride) with low content of head-to-head chain imperfections. J . Polym. Sci. Part A: Polym. Chem. 1978, 16 (11), 3039-3044 DOI: 10.1002/pol.1978.170161135.

21. Tatemoto, M. In The first Regular Meeting of Soviet-Japanese Fluorine Chemists, Tokyo, 1979; Tokyo, 1979.

22. David, G.; Boyer, C.; Tonnar, J.; Améduri, B.; Lacroix-Desmazes, P.; Boutevin, B. Use of iodocompounds in radical polymerization. Chemical Reviews 2006, 106 (9), 3936-3962 DOI: 10.1021/cr0509612.

23. Vukicevic, R.; Schwadtke, U.; Schmucker, S.; Schafer, P.; Kuckling, D.; Beuermann, S. Alkyne-azide coupling of tailored poly(vinylidene fluoride) and polystyrene for the synthesis of block copolymers. Polym. Chem. 2012, 3 (2), 409-414 DOI: 10.1039/c1py00427a.

24. Banerjee, S.; Ladmiral, V.; Debuigne, A.; Detrembleur, C.; Poli, R.; Améduri, B. Organometallic-Mediated Radical Polymerization of Vinylidene Fluoride. 
Angewandte Chemie International Edition 2018, 57 (11), 2934-2937 DOI: doi:10.1002/anie.201712347.

25. Guerre, M.; Rahaman, S. M. W.; Améduri, B.; Poli, R.; Ladmiral, V. RAFT synthesis of PVDF-b-PVAc block copolymers. Polymer Chemistry 2016, (7), 69186933.

26. Asandei, A. D.; Adebolu, O. I.; Simpson, C. P. Mild-Temperature Mn2(CO)10Photomediated Controlled Radical Polymerization of Vinylidene Fluoride and Synthesis of Well-Defined Poly(vinylidene fluoride) Block Copolymers. J. Am. Chem. Soc. 2012, 134 (14), 6080-6083 DOI: 10.1021/ja300178r.

27. Debuigne, A.; Hurtgen, M.; Detrembleur, C.; Jerome, C.; Barner-Kowollik, C.; Junkers, T. Interpolymer radical coupling: A toolbox complementary to controlled radical polymerization. Prog. Polym. Sci. 2012, 37 (Copyright (C) 2015 American Chemical Society (ACS). All Rights Reserved.), 1004-1030 DOI: 10.1016/j.progpolymsci.2012.01.003.

28. Allan, L. E. N.; Perry, M. R.; Shaver, M. P. Organometallic mediated radical polymerization. Progress in Polymer Science 2012, 37 (1), 127-156 DOI: https://doi.org/10.1016/j.progpolymsci.2011.07.004.

29. Poli, R. Relationship between one-electron transition metal reactivity and radical polymerization processes. Angew. Chem., Int. Ed. 2006, 45, 5058-5070.

30. Kaneyoshi, H.; Matyjaszewski, K. Effect of Ligand and n-Butyl Acrylate on Cobalt-Mediated Radical Polymerization of Vinyl Acetate. Macromolecules 2005, 38 (20), 8163-8169 DOI: 10.1021/ma051433v.

31. Kermagoret, A.; Debuigne, A.; Jerome, C.; Detrembleur, C. Precision design of ethylene- and polar-monomer-based copolymers by organometallic-mediated radical polymerization. Nat. Chem. 2014, 6 (3), 179-187 DOI: 10.1038/nchem.1850.

32. Ding, D.; Pan, X.; Zhang, Z.; Li, N.; Zhu, J.; Zhu, X. A degradable copolymer of 2-methylene-1,3-dioxepane and vinyl acetate by photo-induced cobalt-mediated radical polymerization. Polymer Chemistry 2016, 7 (33), 5258-5264 DOI: 10.1039/C6PY01061J.

33. Wang, F.-S.; Wang, T.-F.; Lu, H.-H.; Ao-Ieong, W.-S.; Wang, J.; Chen, H.-L.; Peng, C.-H. Highly Stretchable Free-Standing Poly(acrylic acid)-block-poly(vinyl alcohol) Films Obtained from Cobalt-Mediated Radical Polymerization. Macromolecules 2017, 50 (16), 6054-6063 DOI: 10.1021/acs.macromol.7b00700.

34. Banerjee, S.; Bellan, E.; Gayet, F.; Debuigne, A.; Detrembleur, C.; Poli, R.; Améduri, B.; Ladmiral, V. Bis(formylphenolato)cobalt(II)-Mediated Alternating Radical Copolymerization of tert-Butyl 2-Trifluoromethylacrylate with Vinyl Acetate. Polymers 2017, 9 (12), 702.

35. Debuigne, A.; Caille, J.-R.; Jérôme, R. Synthesis of End-Functional Poly(vinyl acetate) by Cobalt-Mediated Radical Polymerization. Macromolecules 2005, 38 (13), 5452-5458 DOI: 10.1021/ma047726q.

36. Banerjee, S.; Soulestin, T.; Patil, Y.; Ladmiral, V.; Ameduri, B. Towards new strategies for the synthesis of functional vinylidene fluoride-based copolymers with tunable wettability. Polymer Chemistry 2016, 7 (24), 4004-4015 DOI: 10.1039/C6PY00508J.

37. Debuigne, A.; Champouret, Y.; Jérôme, R.; Poli, R.; Detrembleur, C. Mechanistic Insights into the Cobalt-Mediated Radical Polymerization (CMRP) of Vinyl Acetate with Cobalt(III) Adducts as Initiators. Chemistry - A European Journal 2008, 14 (13), 4046-4059 DOI: doi:10.1002/chem.200701867.

38. Debuigne, A.; Caille, J.-R.; Detrembleur, C.; Jérôme, R. Effective Cobalt Mediation of the Radical Polymerization of Vinyl Acetate in Suspension. Angewandte 
Chemie International Edition 2005, 44 (22), 3439-3442 DOI: doi:10.1002/anie.200500112.

39. Cordella, D.; Kermagoret, A.; Debuigne, A.; Riva, R.; German, I.; Isik, M.; Jérôme, C.; Mecerreyes, D.; Taton, D.; Detrembleur, C. Direct Route to Well-Defined Poly(ionic liquid)s by Controlled Radical Polymerization in Water. ACS Macro Letters 2014, 3 (12), 1276-1280 DOI: 10.1021/mz500721r.

40. Spier, E.; Neuenschwander, U.; Hermans, I. Insights into the Cobalt(II)Catalyzed Decomposition of Peroxide. Angewandte Chemie International Edition 2013, 52 (5), 1581-1585 DOI: doi:10.1002/anie.201207920.

41. Bryaskova, R.; Detrembleur, C.; Debuigne, A.; Jérôme, R. Cobalt-Mediated Radical Polymerization (CMRP) of Vinyl Acetate Initiated by Redox Systems: Toward the Scale-Up of CMRP. Macromolecules 2006, 39 (24), 8263-8268 DOI: 10.1021/ma060339r.

42. Debuigne, A.; Jérôme, C.; Detrembleur, C. Organometallic-mediated radical polymerization of 'less activated monomers': Fundamentals, challenges and opportunities. Polymer 2017, 115, 285-307 DOI: https://doi.org/10.1016/j.polymer.2017.01.008.

43. Debuigne, A.; Caille, J.-R.; Jérôme, R. Highly Efficient Cobalt-Mediated Radical Polymerization of Vinyl Acetate. Angewandte Chemie International Edition 2005, 44 (7), 1101-1104 DOI: doi:10.1002/anie.200461333.

44. Golzari, N.; Adams, J.; Beuermann, S. Inducing beta Phase Crystallinity in Block Copolymers of Vinylidene Fluoride with Methyl Methacrylate or Styrene. Polymers 2017, 9 (8), DOI: 10.3390/Polym9080306.

45. Bruno, A. Controlled Radical (Co)polymerization of Fluoromonomers. Macromolecules 2010, 43 (24), 10163-10184 DOI: 10.1021/ma1019297.

46. Nzé, R.-P.; Colombani, O.; Nicol, E. Synthesis of poly(vinyl laurate)-bpoly(vinyl stearate) diblock copolymers by cobalt-mediated radical polymerization in solution. Journal of Polymer Science Part A: Polymer Chemistry 2012, 50 (19), 40464054 DOI: doi:10.1002/pola.26205.

47. Lu, Z.; Fryd, M.; Wayland, B. B. New Life for Living Radical Polymerization Mediated by Cobalt(II) Metalloradicals. Macromolecules 2004, 37 (8), 2686-2687 DOI: $10.1021 / \mathrm{ma} 035924 \mathrm{w}$.

48. Maria, S.; Kaneyoshi, H.; Matyjaszewski, K.; Poli, R. Effect of Electron Donors on the Radical Polymerization of Vinyl Acetate Mediated by [Co(acac)2]: Degenerative Transfer versus Reversible Homolytic Cleavage of an Organocobalt(III) Complex. Chemistry - A European Journal 2007, 13 (9), 2480-2492 DOI: doi:10.1002/chem.200601457.

49. Abel, B.; Assmann, J.; Buback, M.; Grimm, C.; Kling, M.; Schmatz, S.; Schroeder, J.; Witte, T. Ultrafast Decarboxylation of Carbonyloxy Radicals: Influence of Molecular Structure. The Journal of Physical Chemistry A 2003, 107 (45), 94999510 DOI: $10.1021 /$ jp0350823.

50. Xu, W. Z.; Li, X.; Charpentier, P. A. In situ ATR-FT-IR study of the thermal decomposition of diethyl peroxydicarbonate in supercritical carbon dioxide. Polymer 2007, 48 (5), 1219-1228 DOI: https://doi.org/10.1016/j.polymer.2006.12.018.

51. Buback, M.; Frauendorf, H.; Janssen, O.; Vana, P. Electrospray ionization mass spectrometric study of end-groups in peroxydicarbonate-initiated radical polymerization. Journal of Polymer Science Part A: Polymer Chemistry 2008, 46 (18), 6071-6081 DOI: doi:10.1002/pola.22919.

52. Otazaghine, B.; Sauguet, L.; Ameduri, B. Synthesis and copolymerisation of fluorinated monomers bearing a reactive lateral group Part 21. Radical 
copolymerisation of vinylidene fluoride with 2-hydroperfluorooct-1-ene. J Fluorine Chem 2005, 126 (7), 1009-1016 DOI: 10.1016/j.jfluchem.2005.03.006.

53. Gridnev, A. A.; Ittel, S. D. Catalytic Chain Transfer in Free-Radical Polymerizations. Chemical Reviews 2001, 101 (12), 3611-3660 DOI: $10.1021 / \mathrm{cr} 9901236$.

54. Bellan, E. V.; Thevenin, L.; Gayet, F.; Fliedel, C.; Poli, R. Catalyzed Chain Transfer in Vinyl Acetate Polymerization Mediated by 9-Oxyphenalenone Cobalt(II) Complexes. ACS Macro Letters 2017, 6 (9), 959-962 DOI: 10.1021/acsmacrolett.7b00551.

55. Baradie, B.; Shoichet, M. S. Synthesis of Fluorocarbon-Vinyl Acetate Copolymers in Supercritical Carbon Dioxide: Insight into Bulk Properties. Macromolecules 2002, 35 (9), 3569-3575 DOI: 10.1021/ma010461k.

56. Panchalingam, V.; Reynolds, J. R. New vinylidene fluoride copolymers: Poly(vinyl acetate-co-vinylidene fluoride). Journal of Polymer Science Part C: Polymer Letters 1989, 27 (6), 201-208 DOI: doi:10.1002/pol.1989.140270605.

GRAPHICAL ABSTRACT

For Table of Contents Use only 
Straightforward synthesis of well-defined poly(vinylidene fluoride) and its block copolymers by cobalt-mediated radical polymerization

Panagiotis G. Falireas, ${ }^{\dagger}$ Vincent Ladmiral, ${ }^{\dagger}$ Antoine Debuigne, ${ }^{\dagger}$ Christophe

Detrembleur, ${ }^{*}$ Rinaldo Poli, ${ }^{*}, \xi, \approx$ and Bruno Ameduri ${ }^{*},+$

${ }^{\dagger}$ ICGM CNRS, Univ Montpellier, ENSCM, Montpellier, France.

Center for Education and Research on Macromolecules (CERM), CESAM Research Unit, University of Liege, Sart-Tilman B6a, 4000 Liege, Belgium

${ }^{\S}$ CNRS, LCC (Laboratoire de Chimie de Coordination) and Université de Toulouse, UPS, INPT, 205 route de Narbonne, BP 44099, 31077 Toulouse Cedex 4, France

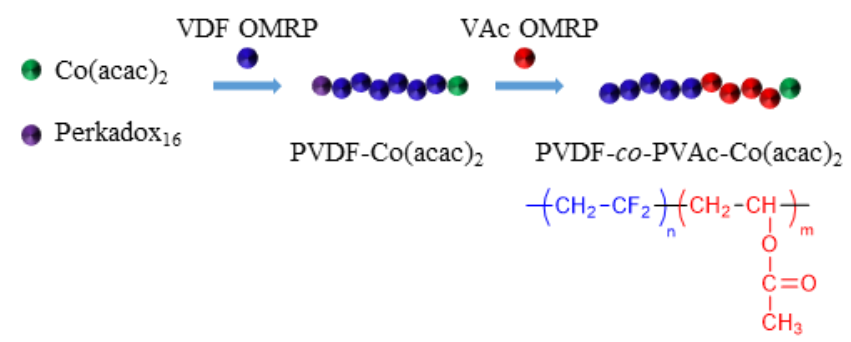

